Article

\title{
Systems Biology Approach Identifies Prognostic Signatures of Poor Overall Survival and Guides the Prioritization of Novel BET-CHK1 Combination Therapy for Osteosarcoma
}

\author{
Pankita H. Pandya ${ }^{1,2,+}+$, Lijun Cheng ${ }^{3,+}$, M. Reza Saadatzadeh ${ }^{1,2,+}+$, \\ Khadijeh Bijangi-Vishehsaraei ${ }^{1,2}$, Shan Tang ${ }^{3}$ D, Anthony L. Sinn ${ }^{4}$, Melissa A. Trowbridge ${ }^{4}$, \\ Kathryn L. Coy ${ }^{4}$, Barbara J. Bailey ${ }^{2}$, Courtney N. Young ${ }^{2}$, Jixin Ding ${ }^{2}$, Erika A. Dobrota ${ }^{2}$, \\ Savannah Dyer ${ }^{4}$, Adily Elmi ${ }^{2}$, Quinton Thompson ${ }^{2} \mathbb{D}$, Farinaz Barghi ${ }^{2,5}$, Jeremiah Shultz ${ }^{2}$, \\ Eric A. Albright ${ }^{6}$, Harlan E. Shannon ${ }^{2}$, Mary E. Murray ${ }^{1}$, Mark S. Marshall ${ }^{1}$, \\ Michael J. Ferguson ${ }^{1}$, Todd E. Bertrand ${ }^{7}$, L. Daniel Wurtz ${ }^{7}$ (D), Sandeep Batra ${ }^{1}$ (D), Lang Li ${ }^{3, *}$, \\ Jamie L. Renbarger ${ }^{1,2,6,8, *}$ and Karen E. Pollok 1,2,4,5,9,* \\ 1 Department of Pediatrics, Hematology/Oncology, Indiana University School of Medicine, Indianapolis, \\ IN 46202, USA; phpandya@iu.edu (P.H.P.); msaadatz@iu.edu (M.R.S.); khbijang@iu.edu (K.B.-V.); \\ memurray@iu.edu (M.E.M.); mmarsha@iu.edu (M.S.M.); micjferg@iu.edu (M.J.F.); batras@iu.edu (S.B.) \\ 2 Department of Pediatrics, Herman B Wells Center for Pediatric Research, Indiana University School of \\ Medicine, Indianapolis, IN 46202, USA; bajbaile@iu.edu (B.J.B.); chemenwa@iupui.edu (C.N.Y.); \\ jixinding@gmail.com (J.D.); erzimmer@iu.edu (E.A.D.); adilyelmi09@gmail.com (A.E.); \\ qthomps@iu.edu (Q.T.); fbarghi@iu.edu (F.B.); jeremiahshultz13@gmail.com (J.S.); heshanno@iu.edu (H.E.S.) \\ 3 Department of Biomedical Informatics, College of Medicine, Ohio State University, Columbus, \\ OH 43210, USA; Lijun.Cheng@osumc.edu (L.C.); Shan.Tang@osumc.edu (S.T.) \\ 4 In Vivo Therapeutics Core, Indiana University Melvin and Bren Simon Comprehensive Cancer Center, \\ Indiana University School of Medicine, Indianapolis, IN 46202, USA; alsinn@iu.edu (A.L.S.); \\ mtrowbri@iu.edu (M.A.T.); kathcoy@iu.edu (K.L.C.); savdyer@iu.edu (S.D.) \\ 5 Department of Medical and Molecular Genetics, Indiana University School of Medicine, \\ Indianapolis, IN 46202, USA \\ 6 Department of Pathology, Indiana University School of Medicine, Indianapolis, IN 46202, USA; \\ eaalbrig@iu.edu \\ 7 Department of Orthopedics Surgery, Indiana University School of Medicine, Indianapolis, IN 46202, USA; \\ tod.bertrand@gmail.com (T.E.B.); dwurtz@iupui.edu (L.D.W.) \\ 8 Indiana Institute of Personalized Medicine, Indiana University School of Medicine, \\ Indianapolis, IN 46202, USA \\ 9 Department of Pharmacology and Toxicology, Indiana University School of Medicine, \\ Indianapolis, IN 46202, USA \\ * Correspondence: Lang.Li@osumc.edu (L.L.); jarenbar@iu.edu (J.L.R.); kpollok@iu.edu (K.E.P.); \\ Tel.: +1-614-292-4778 (L.L.); +1-317-944-8784 (J.L.R.); +1-317-274-8891 (K.E.P.) \\ + Co-first authors with equal contributions.
}

Received: 24 May 2020; Accepted: 14 August 2020; Published: 26 August 2020

check for updates

\begin{abstract}
Osteosarcoma (OS) patients exhibit poor overall survival, partly due to copy number variations $(\mathrm{CNVs})$ resulting in dysregulated gene expression and therapeutic resistance. To identify actionable prognostic signatures of poor overall survival, we employed a systems biology approach using public databases to integrate $\mathrm{CNVs}$, gene expression, and survival outcomes in pediatric, adolescent, and young adult OS patients. Chromosome 8 was a hotspot for poor prognostic signatures. The MYC-RAD21 copy number gain (8q24) correlated with increased gene expression and poor overall survival in $90 \%$ of the patients $(n=85)$. MYC and RAD21 play a role in replication-stress, which is a therapeutically actionable network. We prioritized replication-stress regulators, bromodomain and extra-terminal proteins (BETs), and CHK1, in order to test the
\end{abstract}


hypothesis that the inhibition of BET + CHK1 in MYC-RAD21+ pediatric OS models would be efficacious and safe. We demonstrate that MYC-RAD21+ pediatric OS cell lines were sensitive to the inhibition of BET (BETi) and CHK1 (CHK1i) at clinically achievable concentrations. While the potentiation of CHK1i-mediated effects by BETi was BET-BRD4-dependent, MYC expression was BET-BRD4-independent. In MYC-RAD21+ pediatric OS xenografts, BETi + CHK1i significantly decreased tumor growth, increased survival, and was well tolerated. Therefore, targeting replication stress is a promising strategy to pursue as a therapeutic option for this devastating disease.

Keywords: osteosarcoma; precision genomics; molecular signature; biomarkers; MYC; RAD21; CHK1; BETs

\section{Introduction}

High-grade osteosarcoma (OS) is the most common primary bone cancer in children, as well as in adolescents and young adults (AYA) [1,2]. The aggressiveness of this disease is highlighted by the fact that $40 \%$ of OS patients develop metastases over time, with $15-20 \%$ of OS patients already exhibiting metastases at initial diagnosis [3]. Although the etiology of OS is still unclear, studies have found that mesenchymal stem cells with partial commitment to the osteoblastic lineage acquire genetic mutations that contribute to the onset of OS [3]. Despite a decrease in childhood cancer-related mortality rates due to advancements in therapeutic approaches, the survival rates for pediatric and AYA OS patients have remained unchanged in the last 30 years [4]. In contrast to other pediatric sarcomas, OS lacks a specific oncogenic driver, which further complicates the identification of therapeutic targets [5]. Additionally, in the last 3-4 decades, early phase clinical trials have failed to show promise for the treatment of not only primary OS, but also the more aggressive (relapsed/refractory) form of the disease [6]. The rarity of this disease and small patient populations continue to pose a challenge for initiating new clinical trials for pediatric and AYA OS patients [7]. Therefore, it is critical to understand the molecular heterogeneity and identify biomarkers within the complex genetic landscape of OS, so that actionable targets can ultimately be tested in clinical trials [3].

A detailed understanding of the molecular mechanisms involved in OS pathogenesis is helping to delineate potential prognostic biomarkers as well as predictive biomarkers of therapeutic response in this disease [4,8]. A number of efforts have focused on the large-scale characterization of genetic, epigenetic, and transcriptional changes to identify novel targets or combinations of targets that are promising candidates for testing in clinical trials for pediatric and AYA OS [4]. OS is characterized by various copy number variation (CNV)-based genomic instabilities, such as copy number gains in chromosome arms $6 p, 8 q$, and $17 p$, among many others $[9,10]$. In our previous study, we utilized publicly available datasets to integrate patient $\mathrm{CNVs}$ and survival outcomes with in-vitro drug response data associated with specific CNVs in pediatric sarcoma cell lines [11]. Studies by others have revealed OS-related CNVs in many potential oncogenes, such as RUNX2, CDC5L, VEGFA, PIM1, E2F3, TWIST, MYC, PRIM1, CDK4, MDM2, COPS3, PMP22, and MAPK7 [12-27]. Tumor suppressors have also been reported in OS-related CNV studies and include deletions in INK4A, ARF, INK4B, WWOX, and TP53 [13,28-32]. While these studies investigated correlations between CNVs or gene expression and patient outcomes [5,33-37], they did not comprehensively integrate genome-wide discovery with $\mathrm{CNVs}$, gene expression, and patient outcomes. There is still a critical gap between linking candidate biomarkers of the therapeutic response to actionable targets, signaling pathways, and networks. Moreover, others have demonstrated that single-level analysis which focuses on one level of pathogenesis, such as the transcriptome or proteome, is not sufficient for the identification of novel therapeutic targets in OS [38]. In addition, data from numerous clinical trials indicate that monotherapy will not provide long-term efficacy in aggressive cancers [39]. Therefore, combination 
therapies that target multiple pathways or networks will be required to improve survival outcomes in aggressive cancers such as OS.

To improve the clinical outcome in aggressive OS, it will be necessary to identify combination therapies that are well-tolerated and target a network of nodes or hub genes in perturbed signaling pathways. To this end, a systems biology approach that incorporates "OMICs" data as the foundation for an evaluation of complex biological networks via interdisciplinary collaborations (clinical, pre-clinical, and bioinformatics) can be employed to develop hypothesis-driven approaches for experimental design and analysis $[40,41]$. "OMICS" refers to a full comprehensive study of a biological sample that ranges from its genome, epigenome, transcriptome proteome, metabolome, and its microbiome [42]. This approach helps understand the etiology of the disease and different layers of the "OMICs" approach can be investigated depending on the question of interest [42]. Using the "OMICS" approach in conjunction with "Systems biology" method will help understand the molecular complexity of OS and help identify possible therapeutic networks. Systems biology approach involves large-scale data mining, network analysis, and validation via preclinical in-vivo modeling, all of which can help advance the rational use of combination therapy that is efficacious, but also safe [43]. In the present study, our overall objective was to integrate CNVs and corresponding gene expression data with overall survival in OS to identify prognostic risk signatures and to functionally validate a therapeutically actionable risk signature. Through our integrative bioinformatic analysis, we identified a large number of CNVs that correlate with poor overall survival across the genome. To prioritize and provide rationale for what to investigate in preclinical models of pediatric and AYA OS, we used a "tiered funnel" approach. Four criteria were utilized to select the candidate CNV with a poor prognostic signature that would be investigated in more detail: (1) Correlation of the CNV with poor overall survival in a majority of the OS patients; (2) association of the genes expressed from the CNV with a dysregulated network that can be dually targeted; (3) availability of clinically relevant inhibitors targeting the dysregulated network; and (4) identification of molecularly characterized models of OS harboring the pertinent CNV signature.

The MYC-RAD21+ signature met all four criteria and was prioritized for a preclinical investigation. This signature significantly correlated with increased gene expression and poor survival in $>90 \%$ of OS patients in the Therapeutically Applicable Research to Generate Effective Treatments (TARGET) database [44]. Both of these multifunctional proteins have biological relevance in a number of signaling networks that are dysregulated in cancer [45-49]. Notably, MYC and RAD21 overexpression can serve as a biological indicator of replication stress (RS) that is therapeutically actionable [50]. While high levels of RS can prevent cancer progression by inducing cell death [3,51], moderate RS may allow for an accumulation of $\mathrm{CNVs}$ that elicit gene dysregulation and, ultimately, contribute to tumorigenesis [51]. Therefore, modulation of this dysregulated biological process is very attractive for anti-cancer therapy, especially for genetically complex cancers such as pediatric sarcomas [51,52].

MYC amplification is one of the most common prognostic biomarkers for patients with OS and serves as an attractive therapeutic target [53]. While MYC is a well-known oncogenic driver of OS growth and metastasis, it also plays a critical role in RS by regulating cell cycle machinery, as well as co-localizing to specific nuclear sites associated with early origins of replication [47,52,54]. Notably, MYC has been challenging to directly target. However, inhibitors have been developed for bromodomain and extra-terminal domain (BET) proteins (BRD2,3,4) that block the binding of BETs to acetylated lysines on nucleosomes and decrease the gene expression of transcription factors such as BCL6 and MYC $[55,56]$. While in some molecular contexts, MYC expression can be indirectly inhibited by bromodomain and extra-terminal domain inhibitors (BETi) [57], this is not always the case, as demonstrated in glioblastoma [58]. Regardless, the use of BETi may be promising for treating pediatric OS because an MYC-independent BET function can also affect the expression of RS-related targets $[59,60]$. Our rationale for selecting MYC-RAD21+ as the molecular signature to target was further supported by the fact that a network link between MYC and RAD21 exists, for RAD21 gene expression can be regulated by MYC [61]. RAD21 is often overexpressed in highly replicative cancers [61] and it has 
been reported that RAD21 is amplified in OS and other cancers [62,63]. RAD21 functions as a chromatid cohesion subunit that plays an essential role in DNA replication and repair. Moreover, it has been reported that MYC activation in RAD21 silenced cells results in increased DNA damage and replicative stress $[47,61]$. Although RAD21 cannot be targeted therapeutically, there is emerging evidence that an increased RAD21 protein level correlates with an increased sensitivity to CHK1 inhibitors (CHK1i) [64]. Additionally, mechanistic links may exist between RAD21 and CHK1, for example, in yeast, CHK1 can directly phosphorylate RAD21 [65]. Furthermore, MYC can also directly increase CHK1 gene expression in some cancers [65]. Further rationale for prioritization of the MYC-RAD21+ signature in OS is provided by Rohban et al. They demonstrate that RAD21 may restrain MYC-induced replication stress by cohesion-mediated DNA synthesis to enable faithful clonal expansion of tumor cells [61]. This may help explain why MYC and RAD21 are frequently co-amplified in many cancers [61]. Another reason for MYC and RAD21 co-amplification/co-copy number gain could also be that MYC and RAD21 are in close proximity on the 8q24 amplicon [45].

In this study, we employed a systems biology approach that identified a large number of prognostic signatures that correlate with poor overall survival. As outlined above, the MYC-RAD21+ signature, due to its functional association with RS, was prioritized for the study in preclinical models of pediatric and AYA OS. We tested the hypothesis that in OS models harboring the MYC-RAD21+ risk signature, the dual inhibition of RS regulators BET (OTX-015) + CHK1 (SRA737 or LY2606368) would be efficacious and well-tolerated. Preclinical and clinical (NCT03205176) evaluation of BETi/OTX-015 is under evaluation in refractory solid tumors such as OS [66]. In addition, CHK1i/SRA737 is also being employed in a clinical trial for advanced cancers (NCT02797964, [63]), and CHK1i/LY2606368 is under evaluation by Cincinnati Children's Hospital Medical Center in a Phase 1 Study in mutant TP53 refractory solid and liquid tumors $[8,62,67]$. To the best of our knowledge, our study is the first to integrate the analysis of $\mathrm{CNVs}$, gene expression, and OS patient survival data to prioritize actionable therapeutic targets and functionally validate drug responses in preclinical models of OS with the MYC-RAD21+ signature.

\section{Results}

\subsection{Significant Correlation between Gene Expression Profiles and Survival in Two Independent OS Datasets}

A Cox proportional hazards model illustrated the correlations between gene expression and overall survival from two independent datasets. TARGET ( $n=85$ OS patients; Table S1a) [44] and Gene Expression Omnibus (GEO) GSE16091 database ( $n=34$ OS patients; Table S1b) [68] datasets were utilized to evaluate correlations between gene expression and overall survival. This query was conducted on 16,178 genes available in TARGET and 10,704 genes in the U133A platform within the GSE16091 database. Among the 16,178 total genes evaluated in TARGET, the expression of 1420 genes showed a significant correlation with OS overall survival (Figure 1a, $p<0.05$; Table S2). In the GEO GSE16091 database, the expression of 590 genes out of the 10,704 total genes significantly correlated with overall survival (Figure 1a, $p<0.05$; Table S3). Collectively from the two datasets, 71 expressed genes were found in both databases that showed consistent correlations with OS overall survival, with a false discovery rate of $17 \%$ based on their $p$ values and their direction of association (i.e., positive/negative association between gene expression and overall survival) (Figure 1a, see Venn diagram, Table S2 and Table S3-see genes in red text). Overall survival in OS patients was analyzed based on demographic and clinical variables in TARGET (Figure 1b). In contrast to gender, age, or race, a diagnosis of metastatic disease was the only variable that was significantly associated with poor overall patient survival. Patients with non-metastatic OS at diagnosis had a lower mortality risk than patients diagnosed with metastatic disease at diagnosis (Figure $1 b ; H R=0.21, p<0.0001$ ). No demographic and clinical variables were available for analysis in the GSE16091 OS dataset. 
a.

- TARGET 85 osteosarcoma samples

- 16,178 genes from Affymetrix Human Exon 1.0

- $p<0.05->1420$ genes (expressed)

- Among these 1,349 unique genes to TARGET dataset

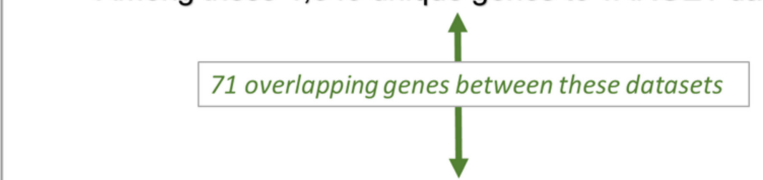

- GSE16091 34 osteosarcoma samples

- 10,704 genes from Affymetrix Human Genome U133A

- $p<0.05->590$ genes (expressed)

- Among these 519 unique genes to GSE16091 dataset

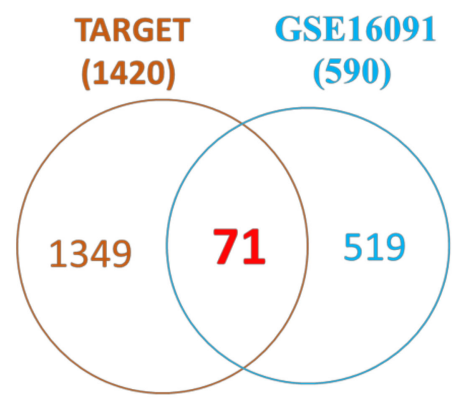

b.

\begin{tabular}{|c|c|c|c|c|c|c|}
\hline Variable & & No. & $\begin{array}{c}\text { Mean(SE) } \\
\text { year }^{A}\end{array}$ & $\begin{array}{c}\text { Median } \\
\text { year }^{A}\end{array}$ & $\mathrm{HR}(\mathrm{SE})^{\mathrm{B}}$ & P-value ${ }^{c}$ \\
\hline \multirow{2}{*}{ Gender } & Female & 38 & $3.66(0.43)$ & 2.78 & \multirow{2}{*}{$0.74(0.28)$} & \multirow{2}{*}{0.42} \\
\hline & Male & 51 & $4.26(0.42)$ & 4.15 & & \\
\hline \multirow{2}{*}{ Age/year } & $>15$ & 41 & $4.09(0.47)$ & 4.02 & \multirow{2}{*}{$1.42(0.53)$} & \multirow{2}{*}{0.36} \\
\hline & $0-15$ & 48 & $3.92(0.41)$ & 3.22 & & \\
\hline \multirow{3}{*}{ Race } & Caucasian & 53 & $4.15(0.34)$ & 4.26 & & \\
\hline & Asian & 7 & $3.18(1.31)$ & 1.94 & $1.33(0.75)$ & 0.71 \\
\hline & $\begin{array}{l}\text { African } \\
\text { American }\end{array}$ & 8 & $5.70(1.61)$ & 5.99 & $0.85(0.65)$ & 0.83 \\
\hline \multirow{2}{*}{$\begin{array}{l}\text { Disease at } \\
\text { Diagnosis }\end{array}$} & Metastatic & 23 & $2.59(0.58)$ & 1.64 & \multirow[b]{2}{*}{$0.21(0.07)$} & \multirow[b]{2}{*}{$<0.0001$} \\
\hline & $\begin{array}{l}\text { Non- } \\
\text { metastatic }\end{array}$ & 66 & $4.48(0.34)$ & 4.32 & & \\
\hline
\end{tabular}

Figure 1. Transcriptome and survival analysis in the two independent overall survival (OS) datasets Therapeutically Applicable Research to Generate Effective Treatments (TARGET) and GSE16091. (a) Correlation of gene expression profiles, and OS patient overall survival in two independent datasets: TARGET and Gene Expression Omnibus (GEO) GSE16091. (b) Survival analysis based on demographic and clinical variables (gender, age, race, and metastasis) present within the TARGET data. Standard error, SE; hazard ratio, HR. A Survival was defined as time in years between diagnosis and death or study endpoint. ${ }^{B}$ HR was calculated by a Cox regression model using the characteristic with a blank HR value as the baseline. ${ }^{\mathrm{C}}$ Relationship between a variable and survival was evaluated using a log-rank test.

\subsection{CNVs Significantly Correlated with the Overall Survival in OS Patients}

The TARGET database not only includes gene expression and overall survival data, but also encompasses CNV data, which is absent from the GEO GSE16091 dataset. Among the overlapping genes identified in both the TARGET and GSE16091 datasets, a significant correlation was observed between the expression of 40 of the 71 overlapping genes with corresponding CNVs in TARGET $(p<0.05$; Table S4-see genes in purple bold text). Within these 40 genes, 14 genes not only showed a significant correlation between gene expression and CNVs, as mentioned above, but also a significant correlation between gene expression and overall survival, as well as between CNVs and overall survival ( $p<0.05$ with a false discovery rate of $8.2 \%$; Figure 2 and Table $S 4$-see genes in green bold text). CNVs such as the presence of copy number gains were observed in MYC, RNF139, SQLE, E1F3H, UBRR5, and IGF1R, whereas MLF2, TXK, PHB, LZTS1, DDX21, FBXW4, CHML, and MAPK8IP3 showed more copy number deletions (Figure 2). Among the 14 genes, 10 genes (MYC,RNF139, SQLE, E1F3H, UBR5, IGF1R, LZTS1, DDX21, FBXW4, and CHML) have HR values > 1, which signifies that those particular genes have a copy number gain and increased gene expression that increase the risk for poor overall survival (Figure 2). The four remaining genes (MLF2, TXK, PHB, and MAPK8IP3) had an HR 
value $<1$, which is indicative of a copy number deletion and decreased gene expression that result in an increased risk for poor overall survival (Figure 2). Moreover, the expression of the non-receptor tyrosine kinase TXK gene, which plays a role in regulating T-Helper 1 (Th1) cells [69], was decreased by 50 -fold at the transcriptome level in OS samples compared to normal bone tissue samples (Figure 2). We further compared the expression of the 14 genes mentioned above in OS samples and non-neoplastic primary normal osteoblasts from an independent GSE14359 dataset (Figure 2). In particular, there was a 310-fold increase in RNA expression of the tumor suppressor gene on chromosome 8p-LZTS1. LZTS1, also known as FEZ1, is a tumor suppressor gene that has been reported to be at decreased levels in various kinds of tumors compared to normal samples [70,71]. LZTS1 produces multiple transcripts, resulting in various isoforms with assorted functions that still need to be investigated [72]. Moreover, while we could observe increased mRNA levels compared to OS samples, the LZTS1 protein levels are not known. The nine other genes were increased by 1.2 15.0 fold [70] (Figure 2). MYC exhibited four-fold change and displayed the most significant correlation between CNV and overall survival, as well as gene expression and overall survival. The role of the other 13 genes which harbor CNVs in OS requires further investigation (Figure 2) [21,67].

\begin{tabular}{|c|c|c|c|c|c|c|c|c|c|c|c|c|c|}
\hline & & & & \multicolumn{9}{|c|}{ TARGET } & \multirow{3}{*}{$\frac{\text { GSE14359 }}{\text { GE: OS vs Normal }}$} \\
\hline \multirow{2}{*}{\multicolumn{2}{|c|}{$\begin{array}{c}\text { Chromosomes } \\
\text { Location }\end{array}$}} & \multirow{3}{*}{$\begin{array}{l}\text { Gene } \\
\text { MYC }\end{array}$} & \multirow{3}{*}{$\begin{array}{l}\text { Gene Name } \\
\text { yce avian myelocytomatosis } \\
\text { viral oncogene homolog }\end{array}$} & \multicolumn{3}{|c|}{$\begin{array}{l}\# \mathrm{CNV} \\
\text { (total 85) } \\
\end{array}$} & \multicolumn{2}{|c|}{ CNV survival } & \multicolumn{2}{|c|}{ GE survival } & \multicolumn{2}{|c|}{$\begin{array}{c}\mathrm{CNV} / \mathrm{GE} \\
\text { Correlation } \\
\end{array}$} & \\
\hline & & & & $\begin{array}{l}\text { CNV } \\
\text { Average }\end{array}$ & $\begin{array}{c}\mathrm{CNV}> \\
2.78\end{array}$ & $\begin{array}{l}\text { CNV } \\
<1.72\end{array}$ & HR & $\mathbf{P}$ & HR & $\mathbf{P}$ & $\mathbf{R}$ & $\mathbf{P}$ & \\
\hline chr8 & $\mathrm{q} 24.21$ & & & 3.86 & 40 & 3 & 1.11 & 0.0013 & 3.18 & 0.0001 & 0.47 & $<0.001$ & 4.07 \\
\hline chr8 & $\mathrm{q} 24.13$ & RNF139 & ring finger protein 139 & 3.68 & 39 & 3 & 1.08 & 0.0008 & 2.23 & 0.0066 & 0.63 & $<0.001$ & 1.64 \\
\hline chr8 & $\mathrm{q} 24.13$ & SQLE & squalene epoxidase & 4.47 & 36 & 3 & 1.04 & 0.0006 & 1.94 & 0.0006 & 0.47 & $<0.001$ & 1.25 \\
\hline chr8 & q24.11 & EIF3H & $\begin{array}{l}\text { eukaryotic translation initiation } \\
\text { factor } 3 \text { subunit } \mathrm{H}\end{array}$ & 3.40 & 33 & 5 & 1.28 & 0.0006 & 2.69 & 0.0057 & 0.53 & $<0.001$ & 2.24 \\
\hline chr8 & $\mathrm{q} 22.3$ & UBR5 & $\begin{array}{c}\text { ubiquitin protein ligase E3 } \\
\text { component } \mathrm{n} \text {-recognin } 5\end{array}$ & 2.80 & 27 & 4 & 1.77 & 0.0017 & 2.18 & 0.0222 & 0.56 & $<0.001$ & 2.61 \\
\hline $\operatorname{chr} 15$ & $\mathrm{q} 26.3$ & IGF1R & $\begin{array}{l}\text { insulin like growth factor } 1 \\
\text { receptor }\end{array}$ & 6.83 & 22 & 6 & 1.01 & 0.0078 & 1.58 & 0.0053 & 0.51 & $<0.001$ & 2.28 \\
\hline $\operatorname{chr} 12$ & p13.31 & MLF2 & myeloid leukemia factor 2 & 2.18 & 10 & 17 & 0.43 & 0.0428 & 0.36 & 0.0196 & 0.66 & $<0.001$ & 1.05 \\
\hline $\operatorname{chr} 4$ & p12 & TXK & TXK tyrosine kinase & 2.08 & 6 & 19 & 0.38 & 0.0301 & 0.14 & 0.0224 & 0.28 & 0.009 & 0.02 \\
\hline $\operatorname{chr} 17$ & $\mathrm{q} 21.33$ & PHB & prohibitin & 2.12 & 5 & 14 & 0.29 & 0.0166 & 0.13 & 0.0007 & 0.55 & $<0.001$ & 1.51 \\
\hline $\operatorname{chr} 8$ & p21.3 & LZTS 1 & $\begin{array}{c}\text { leucine zipper tumor suppressor } \\
1\end{array}$ & 1.85 & 4 & 43 & 1.65 & 0.0379 & 3.31 & 0.0319 & 0.33 & 0.002 & 310.70 \\
\hline $\operatorname{chr} 10$ & $\mathrm{q} 22.1$ & DDX21 & DExD-box helicase 21 & 1.73 & 1 & 50 & 3.33 & 0.0087 & 1.89 & 0.0465 & 0.41 & $<0.001$ & 2.07 \\
\hline $\operatorname{chr} 10$ & $\mathrm{q} 24.32$ & FBXW4 & $\begin{array}{c}\text { F-box and WD repeat domain } \\
\text { containing } 4\end{array}$ & 1.76 & 1 & 44 & 2.65 & 0.0427 & 4.77 & 0.0123 & 0.60 & $<0.001$ & 1.17 \\
\hline chr1 & $\mathrm{q} 43$ & CHML & CHM like, Rab escort protein 2 & 1.82 & 1 & 38 & 3.18 & 0.0123 & 1.61 & 0.0067 & 0.34 & $<0.001$ & 6.03 \\
\hline $\operatorname{chr} 16$ & p13.3 & MAPK8IP3 & $\begin{array}{c}\text { Mitogen-Activated Protein } \\
\text { Kinase } 8 \text { Interacting Protein } 3\end{array}$ & 1.85 & 0 & 38 & 0.21 & 0.0130 & 5.23 & 0.0471 & 0.56 & $<0.001$ & 15.33 \\
\hline
\end{tabular}

Figure 2. Significant correlations between copy number variation (CNV) and OS patient survival, gene expression and OS patient survival, and CNV and gene expression were evident in 14 genes. The expression of these 14 genes across various chromosomes from TARGET was also compared to non-neoplastic primary osteoblasts from GSE14359. CNVs in 14 genes are associated with the overall survival of OS based on TARGET and GSE16091 datasets. HR $>1$ between overall survival and gene expression or CNVs was observed in 10 out of 14 genes, suggesting that copy number gain or increased gene expression results in an increased risk for poor overall survival. CNVs $>2.78$ indicates copy number gain, whereas CNVs $<1.72$ suggests loss/deletion. $\mathrm{HR}<1$ between overall survival and gene expression or CNVs was observed in 4 out of 14 genes, suggesting that copy number deletion or decreased gene expression results in an increased risk for poor overall survival. Notably, $\mathrm{HR}=1$ means that neither gene expression nor CNVs have an effect on the overall survival of OS patients. GE, gene expression.

\subsection{Mapping of CNVs to Their Corresponding Genes that are Associated with Overall Survival in OS Patients}

The remaining bioinformatic analysis focused on the TARGET database, as it includes CNV, gene expression (GE), and clinical outcomes data. Using the TARGET dataset, CNVs that were identified in TARGET were mapped to 26,783 genes (Hg19 genome, https://www.genenames.org/) to standardize the gene annotations and verify the gene nomenclature. Their correlations with the overall survival 
were analyzed using the Cox proportional hazard model. The chromosome distributions of various genes whose $\mathrm{CNV}$ s are significantly associated with overall survival are depicted in Table $1, p<0.05$. Chromosomes 8, 10,11, 15, 16, and 17 have significantly more genes with CNVs that are associated with patient overall survival, and their chromosome enrichment $p$-values are $1.05 \times 10^{-72}, 1.44 \times 10^{-163}$, $3.13 \times 10^{-166}, 1.33 \times 10^{-28}, 4.18 \times 10^{-70}$, and $4.02 \times 10^{-7}$, respectively (red in Table 1 ). In chromosome 8 , the overall survival-associated genes consisted of a higher number of copy number gains than deletions (188 vs. 160, Table 1) compared to other chromosomes. In the other five CNV-enriched chromosomes $(10,11,15,16$, and 17), there were more deletions than copy number gains.

Table 1. Enrichment analysis of significant CNVs observed in genes across various chromosomes. The enrichment odds-ratio (OR) of a chromosome means the ratio of the CNV gene-enriched odds from this chromosome over the other chromosomes' CNV gene-enriched odds. The enrichment $p$-value was calculated from a chi-square test from a 2 by 2 table, in which CNV gene enrichment in one chromosome was compared to all the others. The $p$-value was obtained from a one-sided test for OR $>1$. Chr, chromosome. Chromosomes listed in red have significantly more genes with CNVS associated with patient overall survival.

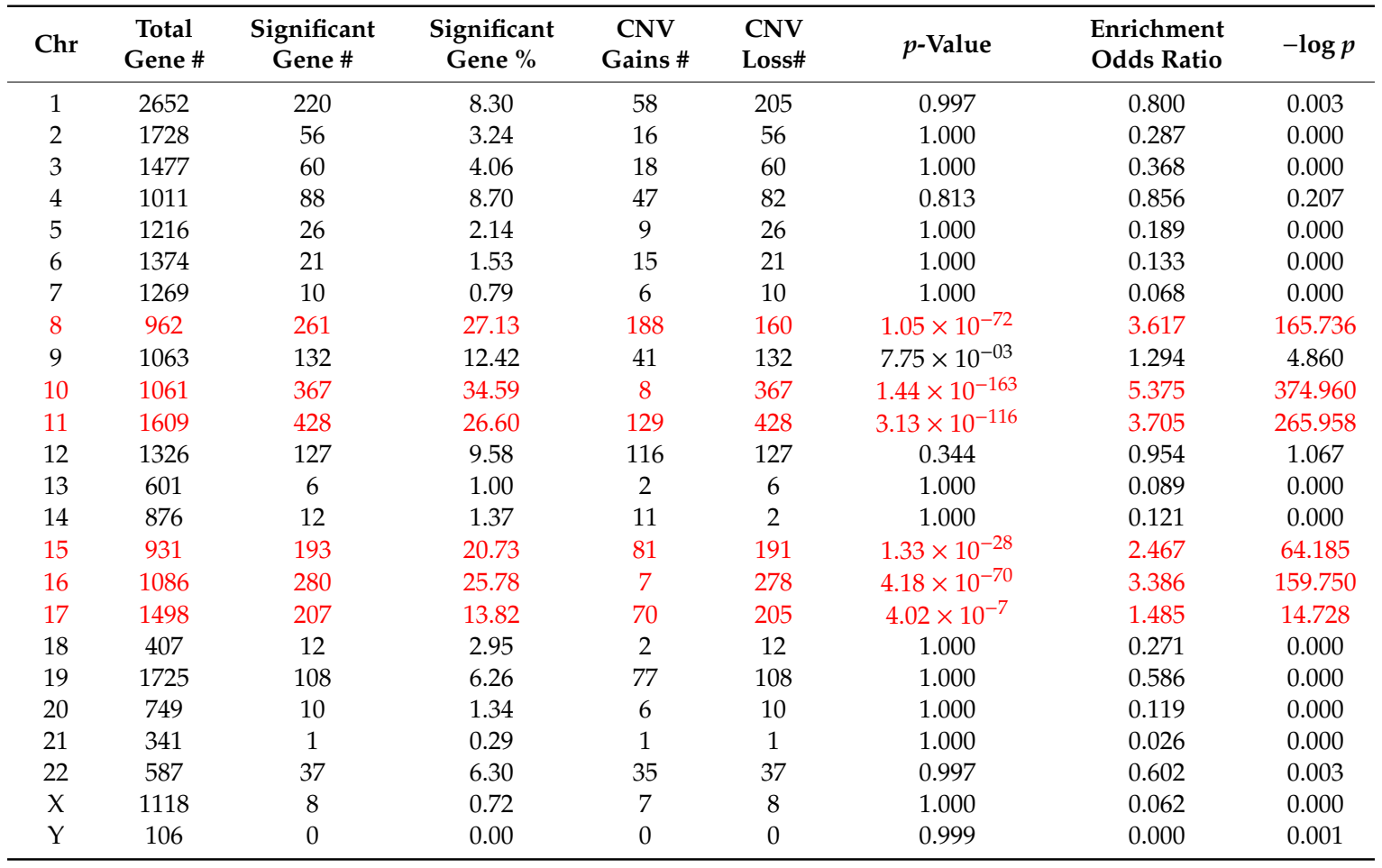

2.4. Multiple CNVs Associated with Increased Gene Expression and Poor Overall Survival in OS Are Present on Chromosome 8

Cox regression analysis conducted on OS patients from the TARGET database $(n=85)$ suggested that CNVs in 2640 genes significantly correlated with an increased risk for a poor prognosis in OS patients. CNVs in 260 genes out of the 2640 were present on chromosome 8 (Figure 3; Table S5). Furthermore, the top 10 genes with $\mathrm{CNVs}$ that were significantly associated with an increased risk for relapse in OS patients were all present on chromosome 8 (Figure 3; Table S5). The MYC-RAD21+ signature was associated with upregulated gene expression and poor overall survival for OS patients based on OS patient data in the TARGET database (Figure 3). Kaplan Meier survival plots generated using the TARGET database demonstrated that MYC copy number gain was significantly associated with decreased overall survival among OS patients (log-rank test $p=0.04, \mathrm{HR}=2.05$ ) (Figure S1a). Kaplan Meier Survival Plot for RAD21 using log-rank test $(\mathrm{p}=0.011, \mathrm{HR}=2.70)$ indicates that copy 
number gain or normal copy number is associated with decreased overall survival in OS patients 1 (log-rank test $p=0.011, \mathrm{HR}=2.7$ ) (Figure S1b).

\section{Chromosome 8}

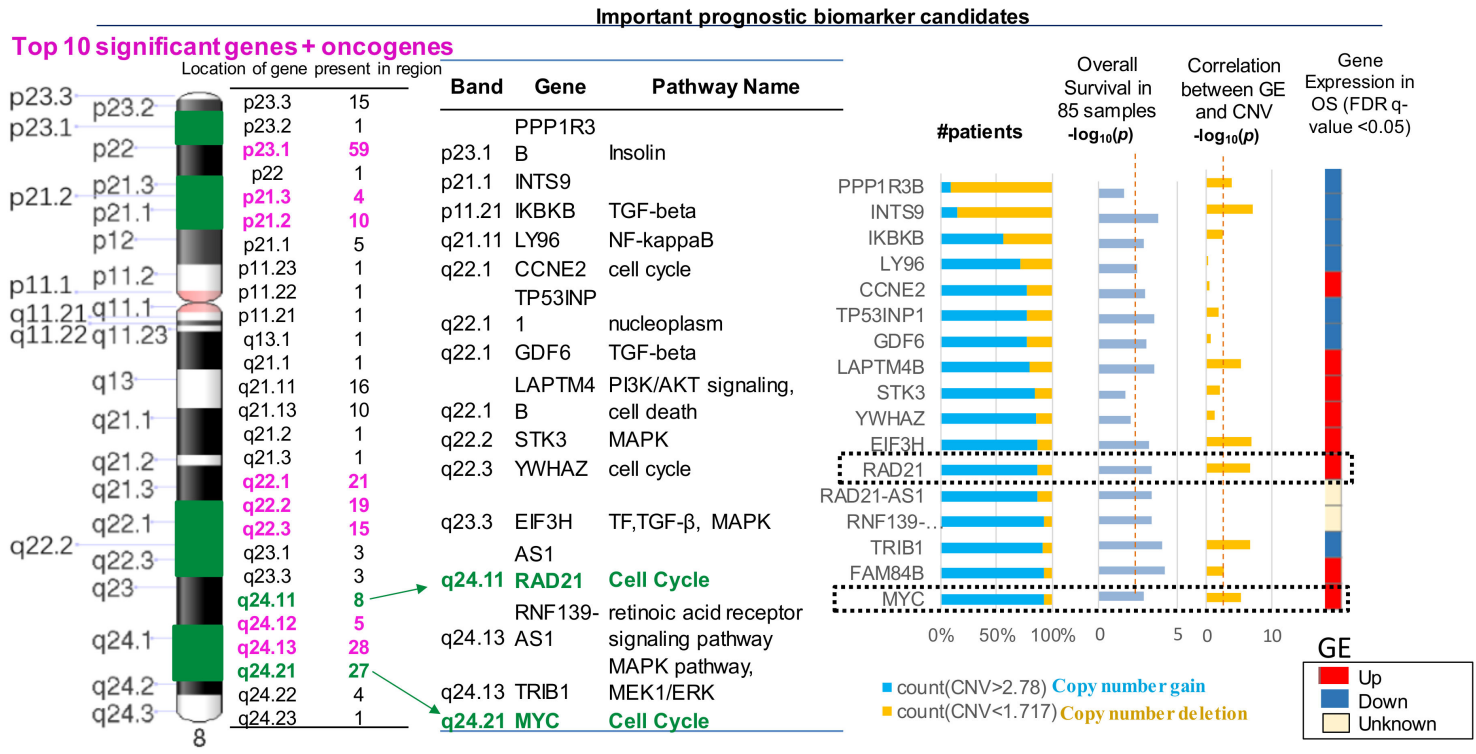

Figure 3. Most significant CNVs correlated with poor overall survival in OS patients are present on chromosome 8 . There are 260 genes with CNVs present on chromosome 8 that are correlated with increased gene expression (GE) and poor survival in OS. The MYC-RAD21+ signature on chromosome $8 \mathrm{q}$ is among the top 10 most significant copy number gains correlated with poor OS survival in over $90 \%$ of patients $(p<0.001)$ and increased GE $(p<0.0001)$. CNV $<1.72$ indicates deletions; CNV $>2.78$ suggests copy number gains. The red dotted line in the columns (i.e., overall survival and correlation between GE and CNV - $\log _{10}(p)$ values) indicates statistically significant differences between the variables, $p<0.05$.

\subsection{Ingenuity Pathway Analysis of Genes with CNVs Significantly Associated with Overall Survival} in OS Patients

A network analysis was performed on the genes of 2640 CNVs that significantly correlated with poor overall survival in TARGET using Ingenuity Pathway Analysis (IPA) (Table S6a, CNV TARGET list). As expected, MYC had a high degree of connectivity with a large number of predicted protein-protein interactions (Table S6b, gene degree by STRING database). Other top interacting network proteins included HRAS, EGFR, and MAPK (Table S6b). RAD21 exhibited a moderate degree of connectivity. Many of the CNVs were related to genes associated with connective tissue disorders (Table S6c). Among the top disease subnetworks designated by IPA, MYC CNVs were associated with skeletal/muscular disorders and RAD21 CNVs were associated with connective tissue disorders (Table S6c). Pathway enrichment analysis of CNVs from TARGET that correlated with poor overall survival indicated a number of links between MYC and MAPK signaling. RAD21 was associated with mitotic and cell cycle pathways (Table S6d). 


\subsection{Prioritization of the MYC-RAD21+Risk Signature for Investigations in Pre-Clinical Models of Pediatric and AYA OS}

The -OMICS analyses we interrogated were genome wide and provided a number of potential targets for investigation. These analyses not only confirmed previous data obtained from others, but also integrated independent data sets to enhance the identification and prioritization of CNVs that significantly correlate with GE and overall survival in pediatric and AYA OS patients. As mentioned above, there were 260 genes with CNVs on chromosome 8 that correlated with increased GE and poor survival in OS using the TARGET database. The MYC-RAD21+ signature on chromosome 8q was among the top 10 most significant copy number gains that correlated with increased GE and poor OS survival in $>90 \%$ of the OS patients. Increased levels of MYC and RAD21 can serve as indicators of dysregulated RS in cancer [50]. Therefore, we hypothesized that by inhibiting key regulators of RS that control its severity, RS would increase to intolerable levels and lead to OS cell death. Targeting RS in OS has not been studied in great detail and a number of promising small molecule inhibitors to RS regulators are in clinical trials $[51,54,58,60,63]$. In these studies, we utilized in-vitro and in-vivo models of pediatric and AYA OS that harbor the MYC-RAD21 CNV+ risk signature to explore the efficacy of inhibiting two RS regulators: BETs and CHK1.

\subsection{In Vitro Assessment of Cell Growth in MYC-RAD21+ Pediatric OS Lines Following the Pharmacological Inhibition of BET Proteins and CHK1}

A panel of established pediatric OS cell lines (Saos2, Saos2-LM7, MG63, G292, and U2OS), as well as an OS xenoline derived from the TT2-77 patient-derived xenograft (PDX), were selected for in vitro screening with BETi and CHK1i. Whole genome sequencing (WGS) of OS cell lines indicated that copy number gains of MYC and RAD21 ranged from 3 to 12 and 0 to 7 copies, respectively (Table S7). Copy number gains do not necessarily correlate with increased gene and/or protein expression due to transcriptional and post-transcriptional regulation [73]. Therefore, the expression of pertinent targets (MYC, RAD21, CHK1, and BET proteins) was confirmed in all OS cell lines by Western blot (Figure S2 and Figure S3). In the U2OS cell line, while an RAD21 copy number gain was not observed (Table S7), RAD21 protein expression was still present at higher levels compared to normal human osteoblasts (NHOSTs) (Figure S2). In the TT2 xenoline, proteins of interest were also compared to the original PDX from which it was established (TT2-77). In contrast to the PDX tissue, the proteins of interest in the TT2-77 xenoline were expressed at higher levels. This is likely attributable to murine stromal components estimated from sequencing data to be $\sim 10 \%$. In addition, the TT2 line is presumably a subpopulation of the human tumor cells in the PDX. Notably, BRD4 was lower in the PDX, which is likely due to the fact that the BRD4 antibody only recognizes human BRD4. The other antibodies used for Western blot are specific for human and murine proteins. The BETi/OTX-015 and CHK1i/LY2606368, as single agents, potently blocked cell growth in all of the OS cell lines and the TT2-77 xenoline at clinically relevant concentrations (Figure 4). However, Saos2 and Saos2-LM7 cells were relatively more resistant to CHK1i/SRA737 than the other OS cell lines (Figure 4). The levels of BETi/OTX-015 clinically achievable in human plasma are dose regimen-dependent, with plasma exposure of up to 1-2 $\mu$ M OTX-015 [58]. The $C_{\max }$ of CHK1i/SRA737 that can be safely obtained in the human plasma was approximately $6 \mu \mathrm{M}$ CHK1i/SRA737 [63]. In a phase I study (NCT02203513), an average plasma concentration of $0.1-0.2 \mu \mathrm{M}$ CHK1i/LY2606368 could be obtained over a $24 \mathrm{~h}$ time interval [74]. 
a.

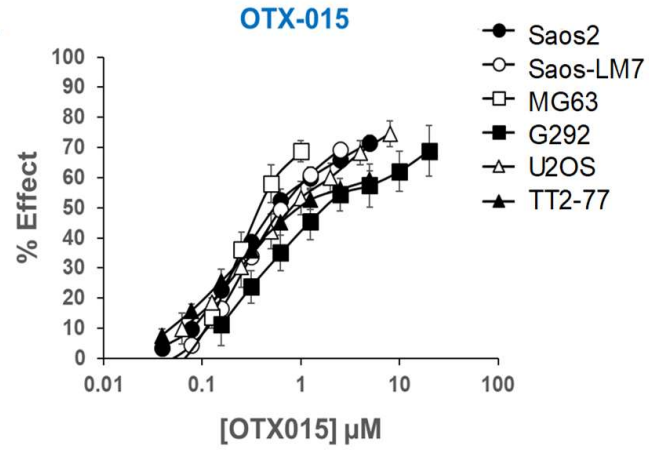

c.

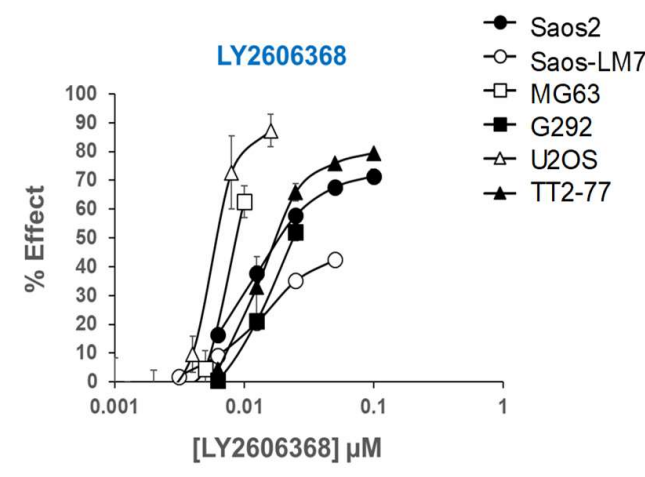

b.

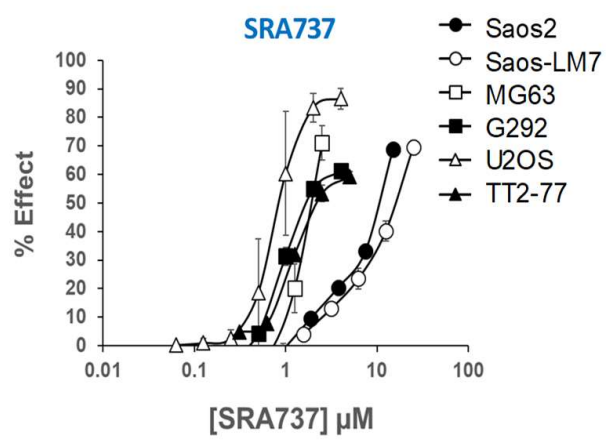

d.

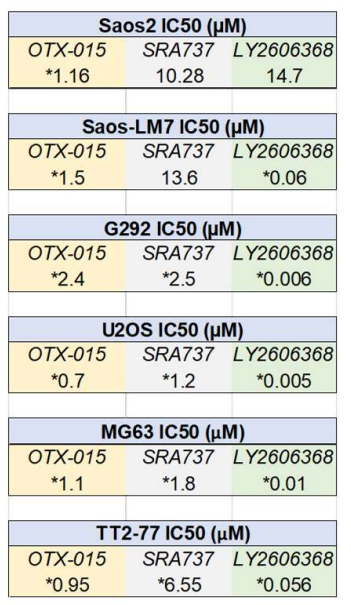

Figure 4. Dose-response curves for OTX-015, SRA737, and LY2606368, evaluated as single agents in a panel of established pediatric OS cell lines and TT2-77 xenoline. Dose-related inhibition of cell growth in the presence of (a) OTX-015, (b) SRA737, and (c) LY2606368 in pediatric OS cell lines. (d) Concentration required as single agents to inhibit 50\% cell growth (IC50) in pediatric OS cell lines. Cell proliferation was determined by methylene blue staining after 5 days of drug exposure. Each point represents the mean of three experiments, each conducted in triplicate. Vertical lines represent \pm one standard deviation and are absent when less than the size of the point. $\mu \mathrm{M}$, micromolar. ${ }^{*}$ Within the range of clinically achievable concentrations in human plasma.

To determine to what extent the simultaneous inhibition of BET proteins and CHK1 blocks growth, MYC-RAD21+ established OS cells and the TT2-77 xenoline were exposed to BETi/OTX-015 plus CHK1i/SRA737 (Table 2a) or BETi/OTX-015 plus CHK1i/LY2606368 (Table 2b) over a broad range of dose ratios. By evaluating a range of dose combinations, insights can be obtained into inhibitor concentrations that need to be achieved in vivo to efficiently inhibit cell growth. Combination drug effects were analyzed for potency and efficacy synergy. An analysis of potency synergy by the combination index (CI) indicated a high degree of synergy in Saos2 and Saos2-LM-7 cell lines (CI $<1.0$ at 20-80\% growth inhibition), while antagonism was observed in the G292, MG63, U2OS, and TT2-77 cell lines (CI > 1.0 at $20-80 \%$ growth inhibition) (data not shown). An analysis of efficacy synergy by Bliss independence indicated that all OS cell lines exhibited at least additive cell-growth inhibition at specific dose ratios of the inhibitors. An additive to the synergistic inhibition of growth in Saos2 or Saos2-LM7 following exposure to BETi/OTX-015 with CHK1i/SRA737 (Table 2a) or CHK1i/LY2606368 (Table 2b) was observed at clinically achievable concentrations over a broad range of dose ratios. In other OS cell lines (G292, MG63, U2OS, and TT2-77 xenoline) exposed to BETi/OTX-015 with CHK1i/SRA737 (Table 2a) or CHK1i/LY2606368 (Table 2b), certain dose ratios resulted in additive growth inhibition at clinically achievable concentrations, while others conferred antagonism, presumably because these OS lines were already quite sensitive to single-agent therapy at clinically achievable concentrations of the inhibitors (see IC50 values, Figure 4). 
Table 2. Analysis of cell growth inhibition in pediatric OS cell lines treated with BET and CHK1 inhibitors. Established OS cells and TT2-77 OS xenoline were treated with varying dose ratios of BETi/OTX-015 and (a) CHK1i/SRA737 or (b) CHK1i/LY2606368. Cell growth was determined by methylene blue staining. Efficacy synergy was determined by Bliss Independence analysis. SEM = standard error mean. *Within the range of clinically achievable concentrations. Clinically achievable doses include

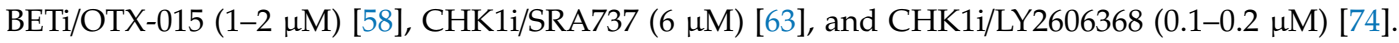
Data are compiled from three independent experiments.

\begin{tabular}{|c|c|c|c|c|c|c|c|c|c|}
\hline \multicolumn{10}{|c|}{ (a) } \\
\hline \multicolumn{10}{|c|}{ Saos2: Mean+SEM Observed-Expected (\% Effect) } \\
\hline \multicolumn{10}{|c|}{ OTX-015 $(\mu \mathrm{M})$} \\
\hline \multirow{6}{*}{ SRA737 ( $\mu$ M) } & & ${ }^{*} 0.04$ & ${ }^{*} 0.08$ & *0.16 & ${ }^{*} 0.31$ & ${ }^{*} 0.63$ & ${ }^{*} 1.25$ & 2.5 & 5 \\
\hline & ${ }^{*} 0.94$ & $3 \pm 0$ & $11 \pm 1$ & $13 \pm 1$ & $16 \pm 0$ & $15 \pm 0$ & $16 \pm 0$ & $15 \pm 0$ & $15 \pm 1$ \\
\hline & *1.88 & $9 \pm 1$ & $16 \pm 1$ & $20 \pm 1$ & $20 \pm 1$ & $19 \pm 0$ & $20 \pm 1$ & $17 \pm 0$ & $15 \pm 0$ \\
\hline & *3.75 & $10 \pm 0$ & $17 \pm 0$ & $19 \pm 1$ & $21 \pm 0$ & $19 \pm 1$ & $17 \pm 1$ & $14 \pm 0$ & $13 \pm 0$ \\
\hline & 7.5 & $7 \pm 0$ & $12 \pm 1$ & $15 \pm 1$ & $16 \pm 0$ & $15 \pm 1$ & $13 \pm 1$ & $12 \pm 0$ & $9 \pm 1$ \\
\hline & 15 & $-3 \pm 1$ & $-1 \pm 0$ & $0 \pm 1$ & $3 \pm 0$ & $3 \pm 0$ & $2 \pm 1$ & $1 \pm 1$ & $-1 \pm 0$ \\
\hline \multicolumn{10}{|c|}{ Saos-LM7: Mean \pm SEM Observed-Expected (\% Effect) } \\
\hline \multicolumn{10}{|c|}{ OTX-015 $(\mu \mathrm{M})$} \\
\hline \multirow{6}{*}{ SRA737 ( $\mu$ M) } & & *0.02 & ${ }^{*} 0.04$ & *0.08 & ${ }^{*} 0.16$ & ${ }^{*} 0.31$ & ${ }^{*} 0.63$ & ${ }^{*} 1.25$ & 2.5 \\
\hline & ${ }^{*} 1.56$ & $6 \pm 1$ & $3 \pm 2$ & $4 \pm 2$ & $7 \pm 2$ & $9 \pm 2$ & $10 \pm 2$ & $8 \pm 1$ & $7 \pm 1$ \\
\hline & *3.13 & $9 \pm 0$ & $7 \pm 1$ & $8 \pm 3$ & $7 \pm 2$ & $9 \pm 2$ & $12 \pm 1$ & $8 \pm 1$ & $6 \pm 1$ \\
\hline & 6.25 & $6 \pm 2$ & $5 \pm 2$ & $7 \pm 1$ & $6 \pm 1$ & $4 \pm 1$ & $4 \pm 2$ & $4 \pm 1$ & $2 \pm 1$ \\
\hline & 12.5 & $2 \pm 1$ & $2 \pm 1$ & $4 \pm 0$ & $4 \pm 1$ & $4 \pm 0$ & $3 \pm 1$ & $3 \pm 1$ & $0 \pm 1$ \\
\hline & 25 & $2 \pm 0$ & $2 \pm 1$ & $0 \pm 3$ & $5 \pm 1$ & $4 \pm 1$ & $3 \pm 1$ & $0 \pm 1$ & $-2 \pm 1$ \\
\hline \multicolumn{10}{|c|}{ MG63: Mean \pm SEM Observed-Expected (\% Effect) } \\
\hline \multicolumn{10}{|c|}{ OTX-015 $(\mu \mathrm{M})$} \\
\hline \multirow{6}{*}{ SRA737 ( $\mu$ M) } & & ${ }^{*} 0.02$ & ${ }^{*} 0.04$ & *0.08 & ${ }^{*} 0.16$ & ${ }^{*} 0.31$ & $* 0.63$ & *1.25 & 2.5 \\
\hline & ${ }^{*} 0.16$ & $-7 \pm 1$ & $-7 \pm 1$ & $-6 \pm 1$ & $-6 \pm 0$ & $-2 \pm 0$ & $0 \pm 1$ & $1 \pm 0$ & $-1 \pm 0$ \\
\hline & *0.31 & $-9 \pm 0$ & $-10 \pm 1$ & $-7 \pm 1$ & $-6 \pm 0$ & $-4 \pm 0$ & $0 \pm 1$ & $1 \pm 1$ & $0 \pm 0$ \\
\hline & ${ }^{*} 0.63$ & $-7 \pm 1$ & $-8 \pm 1$ & $-6 \pm 1$ & $-6 \pm 0$ & $-1 \pm 0$ & $3 \pm 1$ & $6 \pm 0$ & $4 \pm 1$ \\
\hline & *1.25 & $-6 \pm 0$ & $-11 \pm 1$ & $-14 \pm 2$ & $-14 \pm 3$ & $-9 \pm 3$ & $0 \pm 2$ & $3 \pm 3$ & $2 \pm 1$ \\
\hline & $* 2.5$ & $-6 \pm 1$ & $-17 \pm 2$ & $-30 \pm 2$ & $-36 \pm 1$ & $-30 \pm 1$ & $-18 \pm 1$ & $-14 \pm 1$ & $-13 \pm 1$ \\
\hline \multicolumn{10}{|c|}{ G292: Mean \pm SEM Observed-Expected (\% Effect) } \\
\hline \multicolumn{10}{|c|}{ OTX-015 $(\mu \mathrm{M})$} \\
\hline \multirow{6}{*}{ SRA737 ( $\mu$ M) } & & ${ }^{*} 0.13$ & ${ }^{*} 0.25$ & ${ }^{*} 0.5$ & ${ }^{*} 1$ & *2 & $* 4$ & *8 & 16 \\
\hline & ${ }^{*} 0.25$ & $-7 \pm 0$ & $-10 \pm 0$ & $-7 \pm 0$ & $-9 \pm 1$ & $-4 \pm 0$ & $-5 \pm 2$ & $-3 \pm 1$ & $0 \pm 1$ \\
\hline & ${ }^{*} 0.5$ & $-5 \pm 2$ & $-8 \pm 1$ & $-7 \pm 1$ & $-8 \pm 1$ & $-3 \pm 1$ & $-2 \pm 1$ & $0 \pm 1$ & $2 \pm 2$ \\
\hline & ${ }^{*} 1$ & $-13 \pm 3$ & $-18 \pm 2$ & $-17 \pm 2$ & $-17 \pm 2$ & $-11 \pm 1$ & $-10 \pm 2$ & $-7 \pm 2$ & $-3 \pm 2$ \\
\hline & $* 2$ & $-16 \pm 2$ & $-22 \pm 1$ & $-24 \pm 2$ & $-22 \pm 2$ & $-19 \pm 2$ & $-16 \pm 2$ & $-13 \pm 1$ & $-8 \pm 1$ \\
\hline & $* 4$ & $-16 \pm 2$ & $-22 \pm 2$ & $-25 \pm 1$ & $-22 \pm 2$ & $-19 \pm 2$ & $-16 \pm 2$ & $-14 \pm 2$ & $-9 \pm 2$ \\
\hline \multicolumn{10}{|c|}{ U2OS: Mean \pm SEM Observed-Expected (\% Effect) } \\
\hline \multicolumn{10}{|c|}{ OTX-015 ( $\mu \mathrm{M})$} \\
\hline \multirow{6}{*}{ SRA737 $(\mu \mathrm{M})$} & & ${ }^{*} 0.02$ & ${ }^{*} 0.05$ & ${ }^{*} 0.09$ & ${ }^{*} 0.18$ & ${ }^{*} 0.38$ & *0.75 & *1.5 & 3 \\
\hline & ${ }^{*} 0.09$ & $1 \pm 1$ & $-1 \pm 2$ & $0 \pm 1$ & $1 \pm 1$ & $2 \pm 1$ & $0 \pm 0$ & $1 \pm 0$ & $1 \pm 1$ \\
\hline & ${ }^{*} 0.19$ & $0 \pm 2$ & $-3 \pm 2$ & $0 \pm 2$ & $3 \pm 0$ & $2 \pm 1$ & $2 \pm 0$ & $3 \pm 1$ & $2 \pm 1$ \\
\hline & *0.38 & $-8 \pm 2$ & $-11 \pm 1$ & $-10 \pm 1$ & $-7 \pm 3$ & $-6 \pm 3$ & $-5 \pm 3$ & $-4 \pm 3$ & $-3 \pm 3$ \\
\hline & *0.75 & $-8 \pm 3$ & $-9 \pm 3$ & $-10 \pm 4$ & $-10 \pm 2$ & $-10 \pm 2$ & $-10 \pm 1$ & $-9 \pm 0$ & $-9 \pm 1$ \\
\hline & *1.5 & $2+1$ & $-4 \pm 1$ & $-6 \pm 1$ & $-8 \pm 1$ & $-8 \pm 1$ & $-9 \pm 1$ & $-9 \pm 1$ & $-8 \pm 0$ \\
\hline \multicolumn{10}{|c|}{ TT2-77 Xenoline: Mean \pm SEM Observed-Expected (\% Effect) } \\
\hline \multicolumn{10}{|c|}{ OTX-015 ( $\mu \mathrm{M})$} \\
\hline \multirow{6}{*}{ SRA737 $(\mu \mathrm{M})$} & & ${ }^{*} 0.04$ & ${ }^{*} 0.08$ & ${ }^{*} 0.16$ & ${ }^{*} 0.31$ & ${ }^{*} 0.63$ & ${ }^{*} 1.25$ & 2.5 & 5 \\
\hline & ${ }^{*} 0.31$ & $-7 \pm 1$ & $-7 \pm 1$ & $-9 \pm 1$ & $-7 \pm 1$ & $-8 \pm 1$ & $-5 \pm 1$ & $-4 \pm 1$ & $-3 \pm 1$ \\
\hline & ${ }^{*} 0.63$ & $-7 \pm 0$ & $-7 \pm 1$ & $-9 \pm 1$ & $-8 \pm 1$ & $-8 \pm 1$ & $-5 \pm 1$ & $-4 \pm 1$ & $-4 \pm 1$ \\
\hline & *1.25 & $-9 \pm 1$ & $-8 \pm 0$ & $-11 \pm 1$ & $-10 \pm 1$ & $-10 \pm 1$ & $-6 \pm 1$ & $-6 \pm 1$ & $-5 \pm 1$ \\
\hline & $* 2.5$ & $-17 \pm 2$ & $-20 \pm 4$ & $-23 \pm 4$ & $-21 \pm 4$ & $-19 \pm 4$ & $-16 \pm 3$ & $-16 \pm 3$ & $-16 \pm 3$ \\
\hline & *5 & $-17 \pm 0$ & $-21 \pm 1$ & $-25 \pm 2$ & $-25 \pm 2$ & $-24 \pm 3$ & $-21 \pm 3$ & $-21 \pm 3$ & $-21 \pm 3$ \\
\hline
\end{tabular}


Table 2. Cont.

\begin{tabular}{|c|c|c|c|c|c|c|c|c|c|}
\hline \multicolumn{10}{|c|}{ (b) } \\
\hline \multicolumn{10}{|c|}{ Saos2: Mean \pm SEM Observed-Expected (\% Effect) } \\
\hline \multicolumn{10}{|c|}{ OTX-015 $(\mu \mathrm{M})$} \\
\hline \multirow{6}{*}{ LY2606368 ( $\mu \mathrm{M})$} & & *0.01 & ${ }^{*} 0.02$ & ${ }^{*} 0.03$ & ${ }^{*} 0.06$ & ${ }^{*} 0.13$ & *0.25 & ${ }^{*} 0.5$ & $* 1$ \\
\hline & ${ }^{*} 0.00625$ & $1 \pm 1$ & $2 \pm 1$ & $8 \pm 1$ & $9 \pm 2$ & $16 \pm 1$ & $19 \pm 1$ & $21 \pm 2$ & $18 \pm 1$ \\
\hline & *0.0125 & $4 \pm 1$ & $6 \pm 2$ & $8 \pm 1$ & $13 \pm 2$ & $17 \pm 0$ & $18 \pm 0$ & $17 \pm 0$ & $15 \pm 1$ \\
\hline & $* 0.025$ & $1 \pm 1$ & $4 \pm 0$ & $6 \pm 1$ & $9 \pm 1$ & $11 \pm 0$ & $10 \pm 0$ & $10 \pm 0$ & $6 \pm 1$ \\
\hline & ${ }^{*} 0.05$ & $2 \pm 0$ & $2 \pm 1$ & $4 \pm 1$ & $6 \pm 0$ & $6 \pm 1$ & $6 \pm 0$ & $5 \pm 0$ & $3 \pm 1$ \\
\hline & *0.1 & $0 \pm 1$ & $1 \pm 1$ & $2 \pm 1$ & $4 \pm 1$ & $4 \pm 0$ & $4 \pm 0$ & $2 \pm 0$ & $0 \pm 1$ \\
\hline \multicolumn{10}{|c|}{ Saos-LM7: Mean \pm SEM Observed-Expected (\% Effect) } \\
\hline \multicolumn{10}{|c|}{ OTX-015 $(\mu \mathrm{M})$} \\
\hline \multirow{6}{*}{ LY2606368( $\mu \mathrm{M})$} & & ${ }^{*} 0.01$ & ${ }^{*} 0.02$ & ${ }^{*} 0.03$ & ${ }^{*} 0.06$ & ${ }^{*} 0.13$ & ${ }^{*} 0.25$ & ${ }^{*} 0.5$ & *1 \\
\hline & ${ }^{*} 0.00313$ & $3 \pm 1$ & $2 \pm 0$ & $-1 \pm 1$ & $-2 \pm 1$ & $-1 \pm 1$ & $-3 \pm 1$ & $-1 \pm 0$ & $0 \pm 1$ \\
\hline & ${ }^{*} 0.00625$ & $4 \pm 0$ & $3 \pm 1$ & $1 \pm 1$ & $2 \pm 0$ & $0 \pm 3$ & $2 \pm 1$ & $2 \pm 1$ & $1 \pm 1$ \\
\hline & ${ }^{*} 0.0125$ & $7 \pm 1$ & $6 \pm 1$ & $4 \pm 1$ & $6 \pm 2$ & $8 \pm 1$ & $8 \pm 1$ & $7 \pm 1$ & $4 \pm 1$ \\
\hline & ${ }^{*} 0.025$ & $4 \pm 1$ & $3 \pm 2$ & $3 \pm 1$ & $6 \pm 1$ & $7 \pm 1$ & $9 \pm 1$ & $7 \pm 2$ & $4 \pm 2$ \\
\hline & ${ }^{*} 0.05$ & $14 \pm 9$ & $14 \pm 9$ & $13 \pm 7$ & $14 \pm 9$ & $16 \pm 9$ & $16 \pm 7$ & 12left6 & $8 \pm 5$ \\
\hline \multicolumn{10}{|c|}{ MG63: Mean \pm SEM Observed-Expected (\% Effect) } \\
\hline \multicolumn{10}{|c|}{ OTX-015 $(\mu \mathrm{M})$} \\
\hline \multirow{6}{*}{ LY2606368 ( $\mu \mathrm{M})$} & & ${ }^{*} 0.01$ & ${ }^{*} 0.02$ & ${ }^{*} 0.03$ & ${ }^{*} 0.06$ & ${ }^{*} 0.13$ & $* 0.25$ & ${ }^{*} 0.5$ & ${ }^{*} 1$ \\
\hline & ${ }^{*} 0.00063$ & $2 \pm 1$ & $2 \pm 0$ & $1 \pm 1$ & $2 \pm 1$ & $-1 \pm 1$ & $0 \pm 1$ & $0 \pm 2$ & $2 \pm 1$ \\
\hline & ${ }^{*} 0.00125$ & $2 \pm 1$ & $2 \pm 2$ & $1 \pm 1$ & $2 \pm 0$ & $2 \pm 1$ & $1 \pm 0$ & $0 \pm 0$ & $0 \pm 1$ \\
\hline & ${ }^{*} 0.0025$ & $3 \pm 2$ & $3 \pm 3$ & $5 \pm 3$ & $2 \pm 2$ & $2 \pm 1$ & $4 \pm 1$ & $1 \pm 1$ & $2 \pm 1$ \\
\hline & ${ }^{*} 0.005$ & $5 \pm 2$ & $4 \pm 2$ & $2 \pm 2$ & $1 \pm 2$ & $1 \pm 1$ & $0 \pm 1$ & $1 \pm 2$ & $2 \pm 1$ \\
\hline & ${ }^{*} 0.01$ & $-4 \pm 0$ & $-7 \pm 1$ & $-17 \pm 1$ & $-29 \pm 2$ & $-31 \pm 1$ & $-21 \pm 2$ & $-13 \pm 1$ & $-10 \pm 1$ \\
\hline \multicolumn{10}{|c|}{ G292: Mean \pm SEM Observed-Expected (\% Effect) } \\
\hline \multicolumn{10}{|c|}{ OTX-015 $(\mu \mathrm{M})$} \\
\hline \multirow{6}{*}{ LY2606368 ( $\mu \mathrm{M})$} & & ${ }^{*} 0.16$ & ${ }^{*} 0.31$ & ${ }^{*} 0.63$ & *1.25 & 2.5 & 5 & 10 & 20 \\
\hline & $* 0.25$ & $1 \pm 2$ & $-1 \pm 1$ & $1 \pm 1$ & $1 \pm 1$ & $-1 \pm 0$ & $0 \pm 1$ & $2 \pm 1$ & $2 \pm 1$ \\
\hline & ${ }^{*} 0.5$ & $1 \pm 3$ & $-3 \pm 2$ & $-1 \pm 2$ & $1 \pm 1$ & $-1 \pm 1$ & $1 \pm 2$ & $3 \pm 1$ & $5 \pm 2$ \\
\hline & 1 & $-5 \pm 4$ & $-4 \pm 3$ & $-3 \pm 2$ & $0 \pm 2$ & $0 \pm 1$ & $2 \pm 1$ & $4 \pm 1$ & $8 \pm 2$ \\
\hline & 2 & $-11 \pm 3$ & $-13 \pm 2$ & $-10 \pm 2$ & $-7 \pm 2$ & $-5 \pm 1$ & $-1 \pm 2$ & $2 \pm 1$ & $5 \pm 1$ \\
\hline & 4 & $-22 \pm 3$ & $-24 \pm 3$ & $-19 \pm 1$ & $-16 \pm 1$ & $-13 \pm 0$ & $-9 \pm 1$ & $-6 \pm 1$ & $-1 \pm 0$ \\
\hline \multicolumn{10}{|c|}{ U2OS: Mean \pm SEM Observed-Expected (\% Effect) } \\
\hline \multicolumn{10}{|c|}{ OTX-015 $(\mu \mathrm{M})$} \\
\hline \multirow{6}{*}{ LY2606368 ( $\mu \mathrm{M})$} & & ${ }^{*} 0.06$ & ${ }^{*} 0.13$ & ${ }^{*} 0.25$ & ${ }^{*} 0.5$ & $* 1$ & $* 2$ & 4 & 8 \\
\hline & ${ }^{*} 0.00156$ & $2 \pm 5$ & $3 \pm 5$ & $2 \pm 2$ & $-1 \pm 2$ & $-1 \pm 2$ & $1 \pm 3$ & $1 \pm 4$ & $2 \pm 3$ \\
\hline & ${ }^{*} 0.003$ & $1 \pm 2$ & $5 \pm 3$ & $3 \pm 3$ & $0 \pm 1$ & $1 \pm 2$ & $3 \pm 2$ & $2 \pm 3$ & $4 \pm 3$ \\
\hline & ${ }^{*} 0.006$ & $-3 \pm 2$ & $1 \pm 1$ & $-1 \pm 4$ & $-4 \pm 4$ & $-3 \pm 2$ & $0 \pm 2$ & $1 \pm 1$ & $4 \pm 1$ \\
\hline & ${ }^{*} 0.0125$ & $-10 \pm 1$ & $-13 \pm 2$ & $-15 \pm 1$ & $-18 \pm 2$ & $-17 \pm 1$ & $-14 \pm 2$ & $-9 \pm 2$ & $-6 \pm 2$ \\
\hline & ${ }^{*} 0.025$ & $-3 \pm 0$ & $-5 \pm 1$ & $-8 \pm 2$ & $-10 \pm 2$ & $-11 \pm 2$ & $-10 \pm 2$ & $-8 \pm 2$ & $-7 \pm 1$ \\
\hline \multicolumn{10}{|c|}{ TT2-77 Xenoline: Mean \pm SEM Observed-Expected (\% Effect) } \\
\hline & & & & TX-015 ( & & & & & \\
\hline & & ${ }^{*} 0.04$ & ${ }^{*} 0.08$ & ${ }^{*} 0.16$ & ${ }^{*} 0.31$ & ${ }^{*} 0.63$ & ${ }^{*} 1.25$ & 2.5 & 5 \\
\hline & ${ }^{*} 0.00625$ & $-4 \pm 1$ & $-7 \pm 1$ & $-8 \pm 2$ & $-9 \pm 1$ & $-6 \pm 1$ & $-5 \pm 0$ & $-3 \pm 1$ & $-3 \pm 1$ \\
\hline & *0.0125 & $-14 \pm 1$ & $-18 \pm 2$ & $-22 \pm 2$ & $-21 \pm 1$ & $-18 \pm 1$ & $-15 \pm 1$ & $-14 \pm 2$ & $-13 \pm 2$ \\
\hline LY2606368 ( & ${ }^{*} 0.025$ & $-15 \pm 1$ & $-21 \pm 1$ & $-28 \pm 1$ & $-30 \pm 1$ & $-28 \pm 1$ & $-26 \pm 1$ & $-25 \pm 1$ & $-24 \pm 1$ \\
\hline & ${ }^{*} 0.05$ & $-7 \pm 1$ & $-13 \pm 0$ & $-18 \pm 0$ & $-24 \pm 1$ & $-25 \pm 1$ & $-26 \pm 1$ & $-26 \pm 1$ & $-25 \pm 1$ \\
\hline & ${ }^{*} 0.1$ & $-5 \pm 1$ & $-9 \pm 1$ & $-14 \pm 2$ & $-20 \pm 1$ & $-22 \pm 1$ & $-24 \pm 0$ & $-26 \pm 1$ & $-26 \pm 1$ \\
\hline & & & & Key & & & & & \\
\hline & & 10 & & & & & ntagonisn & & \\
\hline & -10 & to 10 & & & & & Additive & & \\
\hline & & o 20 & & & & & ynergistic & & \\
\hline & $20 t$ & $>30$ & & & & Mar & dly Syner & istic & \\
\hline
\end{tabular}

The colors in the table indicate the different levels of additivity, synergism, or antagonism.

\subsection{In Vitro Dual-Inhibition of BET and CHK1 Signifcantly Induces Apoptosis in Saos2 Cells}

As shown above, a blockade of the BET function decreased the resistance to CHK1 inhibition, resulting in a high degree of synergistic growth inhibition at clinically achievable doses in Saos2 and Saos2-LM7 cells (Table 2a,b). We next determined whether synergistic cell-growth inhibition correlated with apoptotic cell death. Saos2 cells were treated with a vehicle, single agent, or BETi/OTX-015 $(0.31 \mu \mathrm{M})$ 
+ CHK1i/SRA737 $(3.75 \mu \mathrm{M})$, which are clinically-achievable doses that induce synergistic cell-growth inhibition (Table 2a). BETi/OTX-015 + CHK1i/SRA737 combination treatment exhibited a significant increase in activated Caspase-3/7 compared to vehicle and single-agent treatments following 2 days of exposure (Figure 5a) that correlated with increased PARP cleavage (a downstream apoptosis marker) [75] (Figure 5b; Figure S4). In addition, flow cytometric analysis of apoptosis by Annexin V and Propidium Iodide staining indicated that by 4 days post-treatment, there was a significant increase in early apoptotic (Figure 5c) and late apoptotic/necrotic (Figure 5d) Saos2 cells treated with BETi/OTX-015 + CHK1i/SRA737 versus the vehicle or single agent. By 5 days post-treatment, only minimal numbers of viable Saos2 cells remained on plates treated with the combination BETi/OTX-015 + CHK1i/SRA737 compared to the vehicle or single agent (Figure S5).

a.

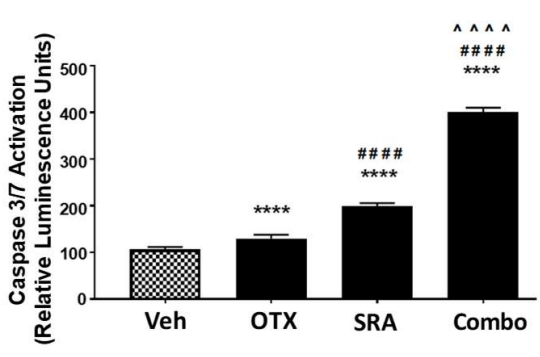

b.

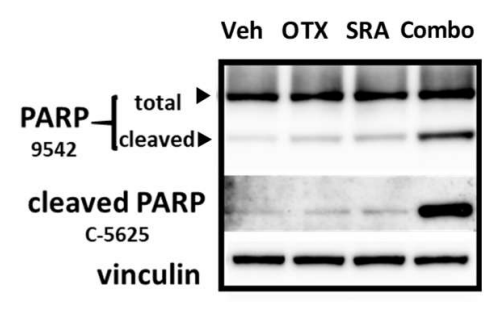

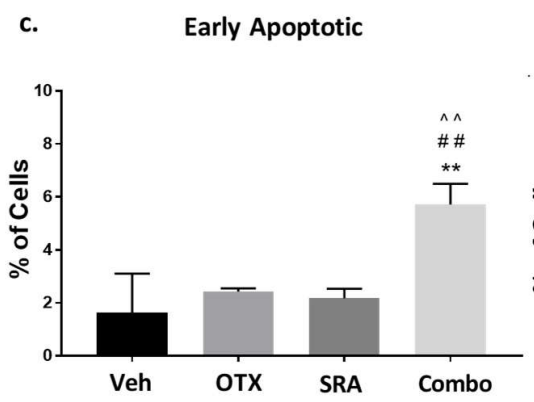

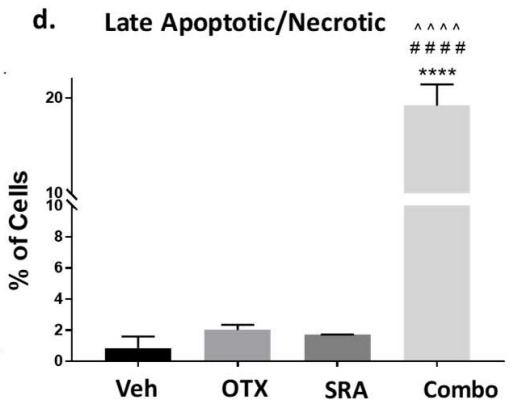

Figure 5. Combination BETi/OTX-015 + CHK1i/SRA737 increases apoptotic cell death in OS cells. (a-b) Saos2 cells were treated with a vehicle, BETi/OTX-015, CHK1i/SRA737, or combination of BETi/OTX-015 + CHK1i/SRA737 for 2 days and analyzed for apoptosis by (a) caspase 3/7 activation via the Apotox assay, and (b) PARP cleavage by Western blot. (c) Saos2 cells were treated with the inhibitor concentrations noted above for 4 days. Apoptosis was analyzed by Annexin V/Propidium Iodide staining and flow cytometry to evaluate (c) early apoptotic (AV+, PI-) and (d) late apoptotic/necrotic $(\mathrm{AV}+, \mathrm{PI}+)$ cells. For the Caspase-3/7 Apotox assay, there were $n=6$ replicates per group and data are representative of two independent experiments. The PARP Western blot was performed once. The apoptosis flow data had $n=3$ technical replicates and is representative of two independent experiments. ${ }^{* *} p<0.01$ vs. vehicle; \#\# $p<0.01$ vs. BETi/OTX-015; ${ }^{\wedge} p<0.01$ vs. CHK1i/SRA737; ${ }^{* * * *} p<0.0001$ vs. vehicle; \#\#\#\# $p<0.0001$ vs. BETi/OTX-015; ${ }^{\wedge} \wedge p<0.0001$ vs. CHK1i/SRA737; data analyzed by one-way ANOVA followed by a Holm-Sidak post-hoc pairwise multiple comparisons test. Veh = vehicle; OTX = BETi/OTX-015 $(0.31 \mu \mathrm{M})$; SRA = CHK1i/SRA737 $(3.75 \mu \mathrm{M})$; Combo = OTX $(0.31 \mu \mathrm{M})+$ SRA $(3.75 \mu \mathrm{M})$.

\subsection{BET Inhibition does not Decrease MYC Protein Expression but does Inhibit OS Cell-Growth by BRD4-Dependent Mechanisms}

There are likely a number of underlying mechanisms that contribute to BETi/OTX-015 + CHK1i/SRA737-mediated growth inhibition and increase apoptosis. As previously mentioned, MYC has been challenging to therapeutically target. Inhibitors of BET proteins, such as BETi/OTX-015, bind to the acetyl-binding grooves of BET proteins (BRD2, 3, 4) and release BET proteins from the chromatin, 
resulting in chromatin compaction and the decreased transcription of genes such as MYC [76-78]. It has also been reported that the inhibition of BET-BRD4 results in MYC-dependent growth inhibition and apoptosis in some OS cell lines [8]. Due to this and the fact that MYC can directly increase CHK1 gene expression in some cancers [65], we hypothesized that BETi/OTX-015 would down-regulate MYC and contribute to decreased CHK1 protein levels. To test this hypothesis, Saos2 cells were treated with a vehicle, single agents, or a combination of BETi/0TX-015 and CHK1i/SRA737. However, there was no difference in MYC or CHK1 levels at 4 or $16 \mathrm{~h}$ post-exposure for single or combination treatment. In addition, the levels of BET proteins (BRD2-4), RAD21, and the loading control (vinculin) were unchanged following drug exposure (Figure 6; Figure S6). Activation of the DNA damage response was evident for exposure to single-agent CHK1i/SRA737 and combination BETi/OTX-015 + CHK1i/SRA737 increased the AKT-mediated phosphorylation of CHK1 at serine 345 -CHK1 S345 (a pharmacodynamic biomarker of DNA damage [79]) and $\gamma \mathrm{H} 2 \mathrm{AX}$ (a pharmacodynamic biomarker of replication stress and double-strand DNA breaks [80]). These results suggest that BETi/0TX-015-mediated effects on MYC protein levels do not represent a mechanism of action that contributes to synergistic cell-growth inhibition (Table 2) and apoptosis (Figure 5) induced by combination BETi + CHK1i in Saos2 OS cells.

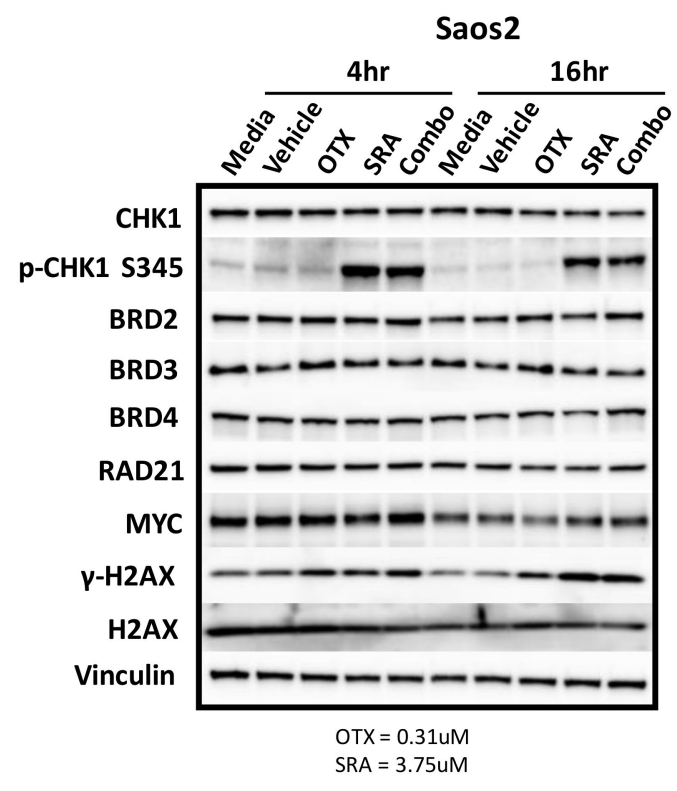

Figure 6. BET inhibition as a single agent or in combination with CHK1i/SRA737 does not decrease the MYC protein. Saos2 cells were treated with controls (media and vehicle), as well as single-agent and combination therapy involving BETi/OTX-015 $(0.31 \mu \mathrm{M})$ and/or CHK1i/SRA737 $(3.75 \mu \mathrm{M})$ for 4 or $16 \mathrm{~h}$. Concentrations were obtained from data in Table 2a. Vinculin serves as the loading control. This was performed once. OTX $=$ BETi/OTX-015 and SRA $=$ CHK1i/SRA737.

We next focused on the role of BRD4 in regulating target gene expression, as well as its role in specifically increasing the sensitivity to CHK1 inhibition. BRD4 transient knock-down in Saos2 cells by siRNA was validated by Western blot (Figure S7). The knockdown (KD) of BRD4 did not have an impact on the levels of MYC protein, confirming that BRD4 does not regulate MYC protein levels in the molecular context of Saos2 cells (Figure S7). In addition, BRD4 KD did not affect the protein expression of BRD2, BRD3, or CHK1 (Figure S7). BRD4 was silenced in Saos2 cells and subsequently treated with CHK1i/SRA737 and cell-growth evaluated (Figure 7). Silencing BRD4 in Saos2 cells resulted in decreased cell growth. In the presence of CHK1i/SRA737, cell growth was further decreased, suggesting that BETi/OTX-015 + CHK1i/SRA737-mediated growth inhibition in Saos2 cells is partially dependent on BRD4. 
control siRNA

100nM BRD4 siRNA

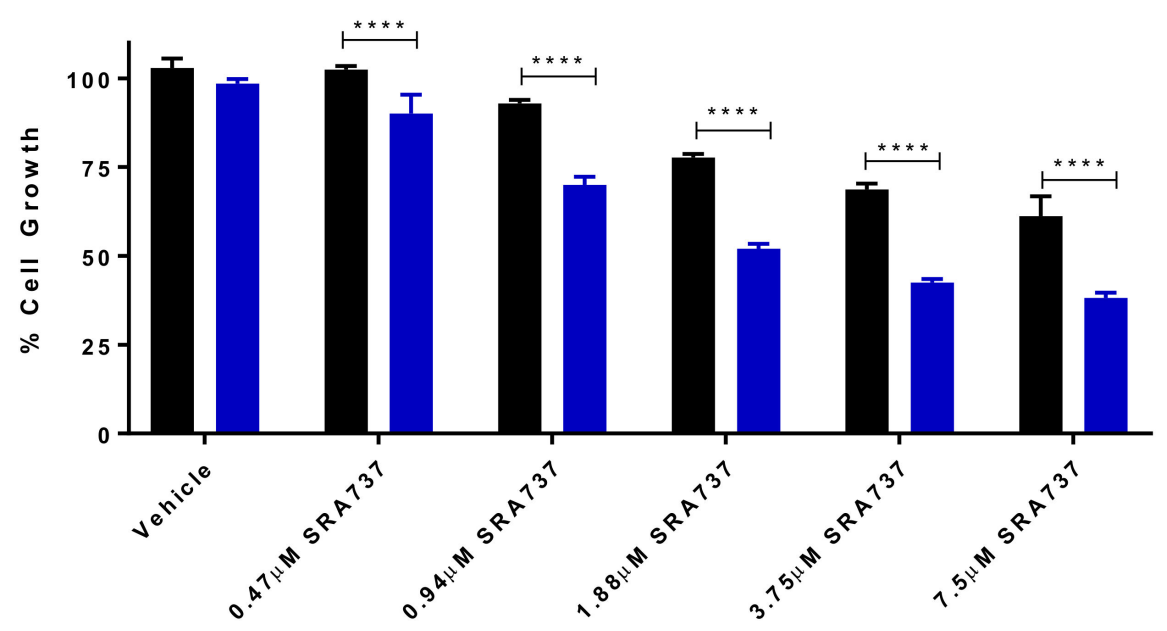

Figure 7. BRD4 knockdown enhances CHK1i/SRA737-mediated growth inhibition. Following transfection for $24 \mathrm{~h}$ (control siRNA or $100 \mathrm{nM}$ BRD4 siRNA pools), Saos2 cells were treated with CHK1i/SRA737 for 5 days and cell growth was evaluated by methylene blue staining. One-way ANOVA followed by a Holm-Sidak post-hoc pairwise multiple comparisons test, $n=3$; **** $p<0.0001$ vs. control siRNA. Data are representative of two independent experiments.

2.10. Dual-Inhibition of BET and CHK1 in a Saos2 Cell Line-Derived Xenograft (CDX) Model Increases the Probability of Survival over Time

To determine if combination BETi and CHK1i is efficacious and safe in vivo, we first used the Saos2 CDX model. This model was selected for an in-vivo study since the in-vitro screening data predicted that the inhibition of BET and CHK1 can synergistically block Saos2 cell growth. SRA737 was prioritized as the CHK1i for in vivo studies due to its safety profile [63], ease of formulation, and oral delivery. In Figure 8a, the tumor volumes are presented when all mice in each group are still under study and have not reached the endpoint tumor volume. During the dosing period, tumors continued to grow in all treatment groups (Figure 8a). All the mice in the vehicle and single-agent groups reached their endpoint tumor volume of $1500 \mathrm{~mm}^{3}$ during the dosing period (Figure 8b). In contrast, none of the mice in the BETi/OTX-015 + CHK1i/SRA737 combination therapy group reached the endpoint tumor volume during the dosing period (Figure 8b; Figure S8a). The Kaplan-Meier survival plot indicated that the BETi/OTX-015 + CHK1i/SRA737 combination therapy resulted in a statistically significant increase in the probability of survival compared to vehicle or single-agent therapy (Figure 8b; Figure S8a). The median survival was 41 days for the vehicle group, 34 days for the CHK1i/SRA737 treatment group, 48 days for the BETi/OTX-015 group, and 65 days for the combination treatment group (Figure $8 \mathrm{~b}$ ). The single and combination treatments were also well-tolerated, as assessed by body weight (Figure S8b). 
a.

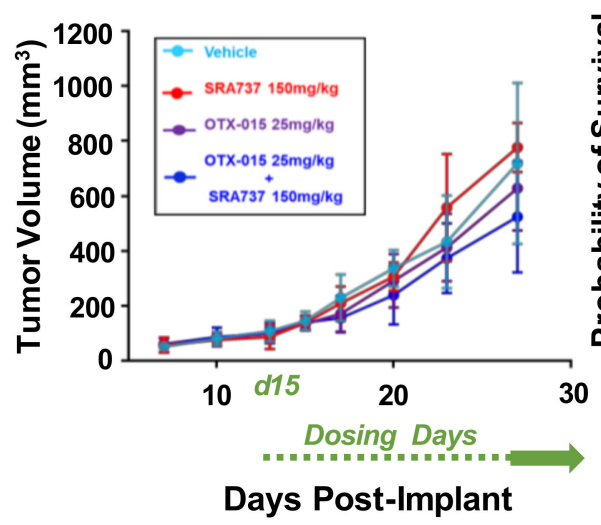

b.

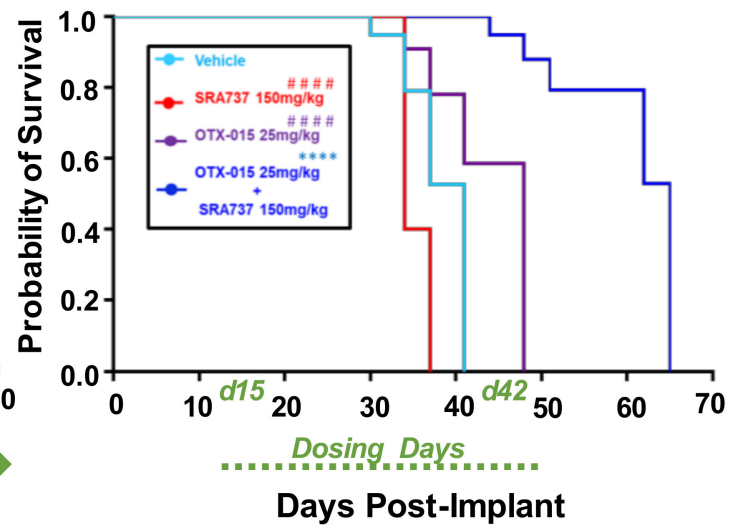

Figure 8. Combination therapy targeting BET and CHK1 increases the survival of mice with MYC-RAD21+ Saos2 CDX. (a) Tumor volumes are shown while all mice are still under study. Once tumor xenografts reached 100-200 $\mathrm{mm}^{3}$, mice were randomized and treated with four 5-day cycles of BETi/OTX-015 (25 mg/kg BID, days 1 through 5 of each cycle) and CHK1i/SRA737 (150 mg/kg SID, days 2 and 4 of each cycle) as single agents or as a combination, or the respective vehicle(s). There were $n=7$ mice for the vehicle group and $n=4-5$ mice for treatment groups. For cycles 1 and 2 of treatment, SRA737 was given $2 \times /$ week and was well-tolerated. As previously mentioned, Saos2 is relatively resistant to SRA737 compared to other OS cell lines (Figure 4). Therefore, since the drug was well-tolerated in cycles 1 and 2, SRA737 doses were increased to $3 \times /$ week in single-agent and combination treatment groups in cycles 3 and 4 . Data represent tumor volumes when all mice were still under study. (b) Kaplan-Meier survival plot. An endpoint tumor volume of $1500 \mathrm{~mm}^{3}$ was used for analysis. ${ }^{* * *} p<0.0001$ vs. vehicle; \#\#\#\# $p<0.0001$ vs. BETi/OTX-015 + CHK1i/SRA737. Dosing period: Day 15-day 42 post-implant (d15-d42).

2.11. Dual-Inhibition of BET and CHK1 in a PDX Model of Relapsed OS Signficantly Arrested Tumor Growth During the Dosing Period and Increased the Probability of Survival over Time

We next compared the effect of single-agent BETi or CHK1i versus combination BETi + CHK1i on the growth of a relapsed OS TT2-77 PDX. Whole genome sequencing indicated that both the OS biopsy at initial diagnosis and the TT2-77 PDX generated from a tumor specimen obtained at resection three years later harbor the MYC-RAD21+ signature (original biopsy and TT2-77 PDX = 4 copies per amplicon, Table S7). As shown previously in Figure 4, the growth of the TT2-77 xenoline was significantly inhibited at clinically relevant concentrations of single-agent BET and CHK1 inhibitors. Bliss analysis indicated an additive effect on growth inhibition at select dose ratios of combination BET and CHK1 inhibitors (Table 1). The in-vivo efficacy data revealed a more pronounced effect on growth inhibition. In TT2-77 PDX mice treated with single-agent BETi or CHK1i, the tumor growth kinetics slowed compared to vehicle-treated mice, but still continued to grow during the dosing period (Day 15-Day 42 post-implant). In mice treated with BETi/OTX-015 + CHK1i/SRA737 combination therapy, tumor growth was significantly halted compared to vehicle or single-agent therapy (Figure 9a). BETi/OTX-015 + CHK1i/SRA737 combination therapy resulted in a statistically significant treatment-related decrease in the TT2-77 tumor volume during the dosing period (days 15-45) (Figure 9a). Once therapy was discontinued, tumor volumes began to increase in the mice treated with BETi/OTX-015 + CHK1i/SRA737 (Figure S9a). Kaplan-Meier survival analysis demonstrated a significant increase in the probability of survival in mice treated with BETi/OTX-015 + CHK1i/SRA737 (Figure 9b; Figure S9b). The median survival was 55 days for the vehicle group, 71 days for the CHK1i/SRA737 treatment group, 64 days for the BETi/OTX-015 group, and 92 days for the combination treatment group (Figure $9 \mathrm{~b}$ ). The single and combination treatment was also well-tolerated, as assessed 
by body weight (Figure S9b), bone marrow cellularity (Figure S9c), and an analysis of vital organ integrity via H\&E staining and pathology analysis (Figure S10).

a.

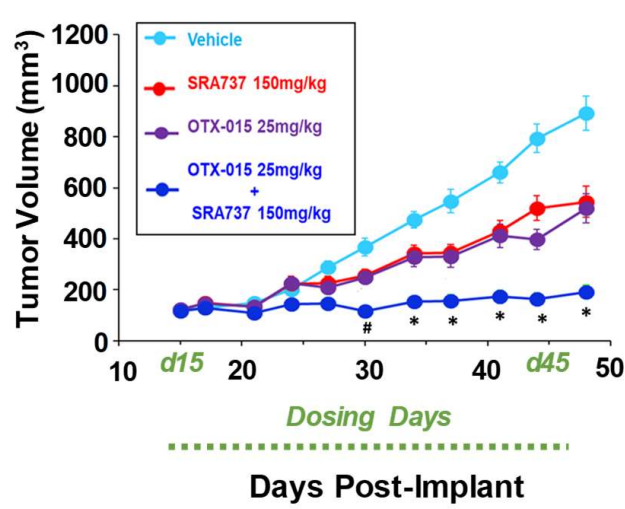

b.

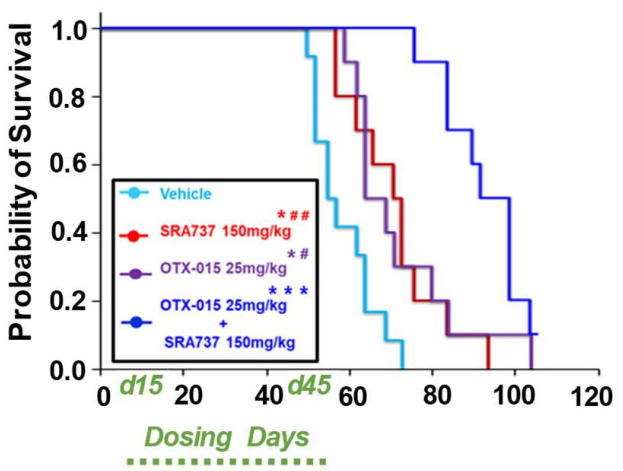

Days Post-Implant

Figure 9. Combination therapy targeting BET and CHK1 significantly inhibited initial tumor growth and increased the survival of mice with a pediatric relapsed MYC-RAD21+ PDX. (a) Tumor volumes are shown while all mice are still under study. Once tumor volumes were $100-200 \mathrm{~mm}^{3}$, mice were randomized ( $n=8-10$ per group) and treated with four 5-day cycles of BETi/OTX-015 ( $25 \mathrm{mg} / \mathrm{kg}$ BID, days 1 through 5 of each cycle) and CHK1i/SRA737 (150 mg/kg SID, days 2 and 4 of each cycle) as single agents or as a combination, or the respective vehicle(s). $\# p<0.05$, combination (BETi/OTX-015 + CHK1i/SRA737) vs. vehicle or single agents. ${ }^{*} p<0.001$ combination (BETi/OTX-015 + CHK1i/SRA737) vs. vehicle or single agents through day 48. (b) Kaplan-Meier survival plot. An endpoint tumor volume of $1500 \mathrm{~mm}^{3}$ was used for analysis. ${ }^{*} p<0.05 ; * * * p<0.001$ vs. vehicle; $\# p<0.05$; \#\# $p<0.01$. Of note: The tumor volume of one mouse in the BETi/OTX-015 + CHK1i/SRA737 combination group was still $<1500 \mathrm{~mm}^{3}$ on the last day of the study (Day 100), so was censored. Dosing period: Day 15-day 45 post-implant (d15-d45).

\section{Discussion}

Despite advancements in multimodal therapeutic approaches, OS still remains challenging to treat due to its genetic heterogeneity and histological variability [3]. Additionally, treatments deemed suitable for adult OS patients may not always be appropriate for pediatric and AYA patients with OS due to differences in tumor biology, genetic alterations, and drug pharmacokinetics in adults versus children [3,81]. The rarity of OS makes it especially challenging to accelerate the development of new drugs to treat this disease due to the cost of drug development and the small number of pediatric patients available to enroll in clinical trials [82]. Therefore, new approaches are needed that utilize population data to identify relevant biomarkers, risk signatures, and targetable pathways that may help guide therapeutic selection for improving the overall survival of pediatric and AYA OS patients.

OS, which is the most common pediatric bone cancer, is characterized by heterogeneous chromosomal instabilities (CINs) ranging from aneuploidies (numerical-CIN) to chromosomal gains or losses (structural- CINs) that can give rise to CNVs [17,83-85]. Since CNVs can encompass a large number of genes, identifying key driver genes is difficult. Others have reported that $>15 \%$ heritable variation in gene expression is due to CNVs [86]. Some of the genes identified by CNV analyses may serve as potential therapeutic targets or biomarkers of biological processes that can be targeted. However, there is limited knowledge on how CNVs are associated with gene expression and patient survival. It is also not clear if poor prognostic CNV signatures linked to increased gene expression can predict therapeutic responses to therapy. Therefore, integrating CNVs with gene expression and patient survival can help identify and prioritize genetic alterations that may have a functional oncogenic or driver effect, and are actionable [86]. One of the key driving forces that promotes the formation of $\mathrm{CNVs}$ is $\mathrm{RS}$, which is a process involving the stalling or collapse of replication forks to 
stop DNA replication [87-90]. RS is an important hallmark in tumorigenesis and is a process unique to cancer cells, thereby making the modulation of this biological process very attractive for anti-cancer therapy [51,52]. In normal healthy cells, if DNA is damaged, then cells either repair it or induce cell death [51]. However, in cancer cells where cell cycle checkpoints or DNA repair pathways are defective, cells attempt to replicate the damaged DNA, which results in fork stalling and the activation of downstream RS pathways [51]. Several extrinsic factors (ultraviolet radiation or genotoxic agents), as well as intrinsic factors (increased oncogene activation), initiate RS [51]. While mild levels of RS induce CIN and contribute to tumorigenesis, high levels of RS may actually protect against cancer progression by inducing cell death [51]. Therefore, identifying actionable biomarkers within the RS pathway that contribute to the complex genetic landscape of pediatric sarcomas and increasing RS to eradicate cancer cells may be an effective therapeutic strategy [3].

The objective of the present study was to expand upon our previous work with a specific focus on pediatric OS, in order to identify, prioritize, and functionally validate molecular biomarkers of therapeutic responses using rationally designed combination therapies [11]. In the current study, we utilized a systems biology approach to interrogate various tiers of pathogenesis (CNVs, gene expression, and patient outcomes) in our OS system. As depicted in Figure 10, we used datasets from TARGET and GSE16091 to compare and correlate CNVs with GE. Additionally, GSE14359 dataset was utilized to assess GE in OS patients versus normal non-neoplastic primary normal osteoblasts from an independent GSE14359 dataset (Figure 2, Figure 10). Results from all 3 datasets contributed to the network pathway analysis reported in this study. The global genome was interrogated to identify CNVs that correlate with gene expression and overall survival. We then used specific criteria to narrow our focus to a statistically significant and actionable molecular signature that can be targeted in pediatric and AYA OS. Therefore, the evaluation and integration of these multi-scale biological networks resulted in prioritization of the MYC-RAD21+ for therapeutic intervention in experimental OS models [91].

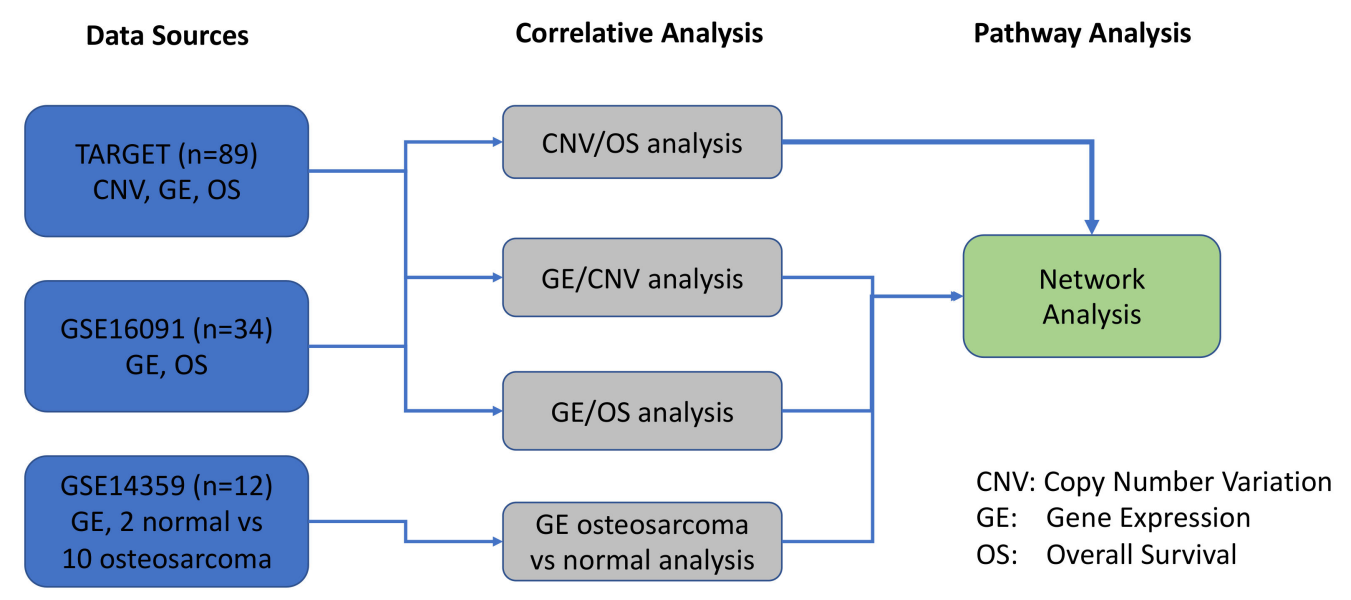

Figure 10. Schematic overview of the datasets and bioinformatics analyses conducted in the study.

Our results from the functional annotation analysis of CNV-associated differentially expressed genes and protein-protein interaction-based pathway analysis indicate that MYC and RAD21 are significant hub proteins. As mentioned above, the MYC-RAD21+ signature not only correlates with poor overall survival in OS, but is also an indicator of RS, which is a biological process that can promote genome instability and likely contributes to the development of CNVs in OS [50,59]. There are a number of mechanistic links between MYC, RAD21, BETs, and CHK1. MYC and RAD21 play a role in RS and the DNA damage response (DDR) pathways [92,93]. MYC, a transcription factor involved in the pathogenesis of OS, has been known to be overexpressed and amplified in localized and metastatic OS, and contributes to therapeutic resistance of the disease [47,94]. Notably, Shi et al. used biological and functional enrichment analysis to demonstrate that MYC is part of the risk signature for OS that is associated with metastatic disease and may help predict an increased 
chance of relapse [95]. Our study not only delves into identifying poor prognostic signatures that are therapeutically actionable, but also functionally validates the MYC-RAD21+ signature as a biomarker of the response to RS-targeted therapy using in-vitro and in-vivo MYC-RAD21+ pediatric OS models.

In addition, MYC-independent effects of BETs can also affect the expression of RS-related targets $[59,60]$. For example, BET-BRD4 can directly contribute to RS by associating with pre-replication factors to induce genes involved in DNA repair $[59,60]$. It is possible that due to the close proximity of MYC and RAD21 on chromosome 8, RAD21 may simply serve as a companion biomarker with no major biological relevance. However, recent studies have demonstrated the functional significance of RAD21 in OS by highlighting that OS cell apoptosis involves the cleavage of RAD21 [46]. As previously stated, CHK1 contributes to the DDR, and in melanomas, increased RAD21 expression associated with an increased sensitivity to CHK1i [64]. Notably, CHK1 has been reported to phosphorylate RAD21, as well in other model systems [65]. Furthermore, RAD21 can also regulate MYC-induced RS [61].

In the present study, we investigated the effectiveness of targeting RS in MYC-RAD21+ pediatric OS cell lines and OS xenograft models. As single agents, BETi/OTX-15, CHKi/SRA737, and CHK1i/LY2606368 were quite potent in terms of cell-growth inhibition in most OS cell lines. The efficacy of the combination BETi + CHK1i, as analyzed by Bliss Independence, revealed differences in the extent of growth inhibition in a panel of OS cell lines and the TT2-77 xenoline. Among these cell lines, Saos2 and Saos2-LM7 were the most resistant to CHK1i/SRA737 single-agent therapy and BETi increased the sensitivity to CHK1i/SRA737, resulting in synergistic cell growth inhibition at clinically achievable concentrations. Dual-inhibition of BET and CHK1 resulted in significant apoptosis that was dependent on BRD4, but did not affect MYC protein levels. In vitro studies on ovarian cancer cells have also shown that therapy involving BET + CHK1 inhibition may be a promising treatment modality [96]. This study demonstrated that inhibition of BRD4 via siRNA or the BETi JQ1 increased heterochromatin protein 1 (HP1) in ovarian cancer cells which limited the DDR and increased sensitivity to CHK1i [96]. Studies are in progress to gain a detailed understanding of the underlying mechanisms of action contributing to the significant growth inhibition observed in pediatric and AYA OS models following exposure to BET + CHK1 inhibition.

In this study, we not only integrated the MYC-RAD21+ signature with CNVs, gene expression, and patient survival data, but we also linked these data with preclinical efficacy and safety data using in vivo models of OS. In a pediatric OS CDX model, as well as a PDX model of relapsed AYA OS, we demonstrated that the simultaneous targeting of BET and CHK1 increased the probability of survival and was well-tolerated. As mentioned previously, the TT2-77 PDX derived from a patient with relapsed OS harbors the MYC-RAD21+ signature. Of critical importance, the original diagnostic biopsy sample from this patient also harbored the MYC-RAD21+ signature, which emphasizes the importance of detecting poor prognostic signatures at diagnosis, which could ultimately lead to innovative clinical trial approaches in OS patients that target poor prognostic signatures up front and prevent relapse in the first place. Studies are in progress to optimize BETi + CHK1i combination therapy in the context of standard-of-care therapy, understand BRD4-dependent mechanisms of action, and study the tumor adaptive response over time. Moreover, studies are in progress to evaluate combination therapies targeting multiple tiers of RS pathways, such as dual-inhibition of BET with ATR or WEE1 [47,48,88]. It will also be informative to evaluate whether BET proteins BRD2 and BRD3 play a role in blocking cell growth. $[47,88,97]$. It is not clear at this time whether the MYC-RAD21 signature is the sole predictor of the therapeutic response to BETi + CHK1i. It is likely that the cellular context and not just the MYC-RAD21 signature will dictate the response to BETi + CHK1i. Moreover, MYC, BETs, RAD21, and $\mathrm{CHK} 1$ protein levels could dictate the sensitivity to the combination of BETi $+\mathrm{CHK} 1 \mathrm{i}$, independent of the MYC-RAD21 CNV status and this is under investigation. In addition, testing novel strategies identified in this study that target other signatures of poor prognosis in pediatric OS, such as the MAPK signaling network, are ongoing. This study provides new information on the safety and efficacy of concomitantly inhibiting BET and CHK1 with the goal of, ultimately, improving the prognosis in children and AYA with aggressive OS, the majority of whom now die of this devastating disease. 


\section{Materials and Methods}

An overview of the systems biology data analysis for osteosarcoma data is presented in the following figure. It started from three osteosarcoma data sources, including TARGET, GSE16091, and GSE14359. Then, correlative analyses were performed for copy number variation (CNV), gene expression (GE), and overall survival (OS), and significant genes and prognostic biomarkers, were selected and overlapped among different correlative analyses. The pathway analysis was performed to explore the underlying molecular mechanisms among these prognostic biomarkers.

\subsection{Osteosarcoma Genomics Datasets for a Systems Biology Approach}

One hundred and three OS were collected from the following publicly accessible databases: NCBI-Gene Expression Omnibus (GEO) (https://www.ncbi.nlm.nih.gov/sites/GDSbrowser/) serials ID GSE16091 and Therapeutically Applicable Research to Generate Effective Treatments (TARGET) (https: //ocg.cancer.gov/programs/target). Two osteosarcoma datasets include CNV, mRNAs, and associated clinical patients' demography.

TARGET: A total of 89 gene expression profiles of OS were obtained from TARGET [44], which was tested by Affymetrix Human Exon 1.0 with 16,178 genes and 88 chromosome copy number analyses and loss of heterozygosity profiles, which was tested by Affymetrix SNP 6.0 Array. Of these gene expression profiles, 85 patients had complete datasets and were included in the analysis. GSE16091: In total, 34 gene expression profiles of OS were obtained from GSE16091 [68], which was tested by Affymetrix Human Genome U133A with 10,704 genes. GSE14359: In order to characterize OS disease genes, we collected GEO series ID GSE14359 [98]. This included 10 expression data from five frozen conventional OS patients, involving 10 conventional OS tissues and two non-neoplastic primary normal osteoblasts cells, using Affymetrix HG U133A microarrays.

\subsection{Gene Annotations for a Systems Biology Approach}

The HUGO Gene Nomenclature Committee (HGNC, http://www.genenames.org/) database provides researchers with standard gene names for the human genome to avoid the complexity of multiple overlapping and conflicting nomenclature systems. The database currently consists of around 24,000 genes and their corresponding approved gene symbols. Each gene has a unique HGNC ID, which makes it easier to identify the gene type. Genes were also annotated with other information, including gene synonyms, uniprot IDs, refseq IDs, previous gene symbols, and a functional description about each gene, all of which aid in integrating information from the NCBI or other databases [99].

\subsection{Correlative Analysis between Gene Expression and Patient Overall Survival}

Gene expression high-throughput data preprocessing: Microarray Human Genome U133A and Affymetrix Human Exon 1.0 data (.cel files) was processed and normalized using the Robust Multi-array Average (RMA) [100] algorithm. The normalized $\log 2$ ratio (healthy/tumor) on probe-sets was annotated for genes for further analysis. The data were analyzed in R [101].

Cox regression (or proportional hazards regression) [102] was analyzed using the Coxph() in R. This analysis investigates the effect between the gene expression or CNVs and patient survival. The confounding factors of race and metastasis status were justified in the multivariate survival model [103].

\subsection{Correlative Analysis between CNV and Patient Overall Survival}

CNV analysis was conducted using Partek Genomics Suite (Partek, Inc., St. Louis, MO, USA). The Genomic Segmentation method from Partek Genomics was used to detect break points and obtain CNV calls from the log intensities of the Affymetrix Genome-Wide Human SNP Array 6.0. Default parameters were used for the detection of copy number gain and deletions: Minimum genomic markers $=10 ; p$-value threshold $=0.001$; signal to noise $=0.3$; and diploid copy number $=1.72$ to 2.78 . 
In other words, $\mathrm{CNV}$ values smaller than 1.72 were categorized as a "deletion" $(-1), \mathrm{CNV}$ values larger than 2.78 were categorized as a "gain" $(+1)$, and CNVs were categorized as "normal" (0).

Cox regression (or proportional hazards regression) [102] was analyzed using the Coxph() in R. This analysis investigates the effect between the gene expression or CNVs and patient survival. The confounding factors of race and metastasis status were justified in the multivariate survival model [103].

\subsection{Correlative Analysis between CNV and Gene Expression}

Correlation analysis between gene expression and $\mathrm{CNV}$ was analyzed using $\mathrm{R}$ package, $\operatorname{lm}()$. The correlation analysis was analyzed at the per-gene level.

\subsection{Differential Expression Calculation}

Differential gene expression (DEG) was analyzed by the R 'limma' package. The Wilcoxon rank sum test was implemented to analyze the differences between sample types. Benjamini and Hochberg adjustment was applied to all initial $p$-values, where applicable, to account for the multiple testing issues. The EdgeR [104] tool was used for RNASeq DEG calculation, which expects raw counts the as input.

\subsection{Pathway Analysis (Gene Enrichment Analysis and Network Analysis)}

GSEA software was used for pathway gene set enrichment analysis. Ingenuity Pathway Analysis (IPA, QIAGEN Redwood City, CA, USA) was used to conduct pathway analysis and identify genes connected to pathways of interest [105]. More specifically, we focused on the IPA networks that were curated from the literature.

\subsection{Cell Lines}

NHOSTs were purchased from Lonza Clonetics and expanded/grown using the Lonza Clonetics Osteoblast Growth Medium, as per the manufacturer's instructions. Established Pediatric OS Cell Lines Saos2, G292, MG63, and U2OS were purchased from ATCC in 2018. Saos-LM7 was a kind gift from Dr. Eugenie S. Klenerman (MD Anderson, Houston, TX, USA). Pediatric OS cell lines (Saos2, Saos-LM7, G292, MG63, and U2OS) were authenticated for their identity/species by DNA fingerprinting analysis using a nine marker short-tandem repeat (STR) analysis (IDEXX BioResearch, Columbia, MO, USA), as described in [106], and were reported to be $100 \%$ human. All cell lines were cryopreserved at a low passage and were negative for mycoplasma (MycoAlert Kit; Lonza, Morristown, NJ, USA). All cell lines were cultured in DMEM containing $10 \%$ FBS. Cells were cultured at $37^{\circ} \mathrm{C}$ with $5 \% \mathrm{CO}_{2}$.

\subsection{Compounds}

OTX-015 and LY2606368 (MedChem Express, Monmouth Junction, NJ, USA) and SRA737 (Chemietek, Indianapolis, IN, USA) were dissolved in $100 \%$ dimethyl sulfoxide (DMSO) for in vitro studies. The final concentration of DMSO for all drugs in all cell cultures was $\leq 0.1 \%$. OTX-015 and SRA737 were dissolved in $10 \%$ DMSO, $20 \%$ PEG400, $5 \%$ Tween 80 , and $65 \%$ water for the in-vivo studies.

\subsection{Cell Proliferation Assay}

OS cell lines were cultured in DMEM containing 10\% FBS and seeded overnight in 96-well plates (3500 cells/well). The next day, cells were treated with varying concentrations of OTX-015, LY2606368, and SRA737 as single agents for 5 days. Following the 5-day treatment, cell growth/proliferation was determined by methylene blue staining, as previously described [106]. Experiments were conducted in sextuplicate and repeated three times. 


\subsection{In Vitro Analysis of Apoptosis by Activated Caspase-3/7}

Saos 2 cells (6000 cells/well) were seeded in a flat-bottom 96-well plate to adhere overnight. The following day, Saos2 cells were treated with appropriate BETi/OTX-015, CHK1i/SRA737, and vehicle concentrations. Treatments was left on the cells for 2 days without the replacement of media. Following the 2 day treatment exposure, the ApoTox-Glo Triplex Assay (Promega, Madison, WI, USA) was used as per the manufacturer's instructions to evaluate the levels of activated caspase-3/7 (a marker for apoptosis) by reading luminescence values. Experiments were conducted in sextuplicate and repeated twice.

\subsection{Apoptosis Flow Cytometry}

Saos-2 cells were treated with a vehicle (DMSO) or $0.31 \mu \mathrm{M}$ BETi/OTX-015 and $3.75 \mu \mathrm{M}$ CHK1i/SRA737, as single agents or in combination. After 96 h, media plus cells were collected, placed in a tube, and washed twice with cold PBS, and $120 \mathrm{uL}$ Annexin V Binding Buffer was added to the cells. Each cell was stained with 5 uL FITC Annexin V (BD Pharmingen, cat\# 556420; Franklin, NJ, USA) and Propidium Iodide Staining Solution (Invitrogen, cat\# 00699050; Grand Island, NY, USA) for $15 \mathrm{~min}$ at room temperature in the dark. Subsequently, $400 \mathrm{uL}$ of 1:10 diluted Annexin V Binding Buffer (BD Pharmingen, cat\# 556454) was added to each tube and stained cells were analyzed by flow cytometry on the BD Fortessa. For each sample, 20,000 cells were collected and analyzed for apoptotic cells by FlowJo Software.

\subsection{Transient Knockdown of BRD4 with siRNA}

ON-TARGET plus non-targeting control and SMARTpool ON-TARGET plus BRD4 siRNAs were purchased from Horizon Discovery. Non-targeting control siRNA sequences were D-001810-10-05: UGGUUUACAUGUCGACUAA, UGGUUUACAUGUUGUGUGA, UGGUUUACAUGUUUUCUGA, and UGGUUUACAUGUUUUCCUA. BRD4 siRNA sequences from smartpool were Pool 1, J-004937-06: AAACCGAGAUCAUGAUAGU; Pool 2, J-004937-07: CUACACGACUACUGUGACA; Pool 3, J-004937-08: AAACACAACUCAAGCAUCG; and Pool 4, J-004937-09: CAGCGAAGACUCCGAAACA. Lipofectamine RNAiMAX (Life Technologies, Grand Island, NY, USA) was used for transfection. For Western blot and proliferation assays, Saos2 cells were transfected with either $100 \mathrm{nM}$ non-targeting control siRNA or $100 \mathrm{nM}$ BRD4 siRNA. For Western blot, cells were seeded overnight in $10 \mathrm{~cm}$ Petri dishes. The next day, cells were transfected with either non-targeting control siRNA or BRD4 siRNA and subsequently collected at 24, 48, and $72 \mathrm{~h}$ post-transfection to assess BRD4 knock-down. For proliferation assays, Saos 2 cells were seeded in 96-well plates overnight, and 1 day post-transfection, the cells were treated with the vehicle, or CHK1i/SRA737 alone or in combination for 5 days to assess cell-growth inhibition.

\subsection{NOD.Cg-Prkdcscid Il2rgtm1Wjl/SzJ (NSG)}

NSG mice were obtained from the on-site breeding colony from the In Vivo Therapeutics Core of the Indiana University Simon Comprehensive Cancer Center. All procedures were approved by the Institutional Animal Care and Use Committee at the IU School of Medicine (IACUC study \# 19052). Animals were maintained under pathogen-free conditions and maintained on a Teklad Lab Animal Diet (TD 2014, Harlan Laboratories USA) with ad libitum access to sterile tap water under a 12-h light-dark cycle at $22-24{ }^{\circ} \mathrm{C}$.

\subsection{Development of an Saos2 CDX Model of OS}

We found that it was challenging to generate sufficient numbers of mice for in vivo studies when xenografts were established by the direct implantation of Saos2 cell suspensions. While tumors grew, the cell growth kinetics were inconsistent between animals. Therefore, to increase the consistency of tumor take and growth kinetics, a two-step approach was utilized. Saos2 CDX were first established 
in female NSG (6-8 week old mice) by the implantation of $5 \times 10^{6}$ Saos 2 cells ( $200 \mu \mathrm{L}$ 1:1 Matrigel to basal RPMI). We found that matching the gender of the tumor sample with the gender of the NSG mice (6-8 weeks old) used for tumor implant improves tumor take and allows for more consistent tumor growth kinetics. Once tumor volumes reached $\sim 1000 \mathrm{~mm}^{3}$, Saos2 tumors were harvested and similar-sized tumor fragments $(2 \times 2 \mathrm{~mm})$ were implanted into the flank of female NSG mice. Growth kinetics were tracked following implantation by an electronic caliper and implanted mice that showed consistent tumor take and growth kinetics were included in the study. In the re-implanted mice, as soon as the tumor volumes were $100-200 \mathrm{~mm}^{3}$, mice were randomized and treated with four 5-day cycles of SRA737, OTX-015, or combination therapy, as listed above in Figure 8.

\subsection{Development of TT2-77 PDX from a Pediatric Patient with Relapsed OS}

TT2-77 is an OS sample derived from a male pediatric OS patient that relapsed in August 2017 and was enrolled in the Precision Genomics Program at Riley Children's Hospital (Indiana Pediatric Biobank IRB \# 1501467439). The PDX was developed as described by Mattar et al. [107]. Briefly, the tumor specimen was cut into fragments and either flash frozen $(5 \times 5 \mathrm{~mm}) /$ cryopreserved $(3 \times 3 \mathrm{~mm})$ to a biobank, or fragment $(2 \times 2 \mathrm{~mm})$ implanted into male NSG mice. The TT2-77 PDX tumors were expanded into larger cohorts of male mice for PDX archiving and for in vivo investigations in this study. Additionally, TT2-77 PDXs were authenticated by STR analysis and MYC-RAD21 copy numbers were obtained from whole genome sequencing (Table S7). For in vivo study set up (Figure 9), once mice tumor volumes reached at least $1000 \mathrm{~mm}^{3}$, the TT2-77 PDX tumor was fragmented. Similar-sized tumor fragments $(2 \times 2 \mathrm{~mm})$ were implanted into the flank of male NSG mice. Growth kinetics were tracked following implantation by an electronic caliper and implanted mice that showed consistent tumor take and growth kinetics were included in the study. In the re-implanted mice, as soon as the tumor volumes were $100-200 \mathrm{~mm}^{3}$, mice were randomized and treated with four 7-day cycles of SRA737, OTX-015, or combination therapy, as described in Figure 9.

\subsection{Development of TT2-77 Xenoline from PDX}

Established TT2 tumors from the PDX model described below were resected, collected $\left(<2000 \mathrm{~mm}^{3}\right)$, and processed for single-cell separation to culture in vitro. Primary PDX tumor tissue was dissociated into a single-cell suspension by mechanical dissociation using the Gentle MACS Dissociator (Miltenyi Biotec, Gaithersburg, MD, USA) and enzymatic degradation of the extracellular matrix using the Human Tumor Dissociation Kit (Miltenyi Biotec; according to the manufacturer's protocol). The cell suspension was washed and centrifuged three times before the cell pellet was re-suspended in DMEM or DMEM/F12 medium containing 2.5\% FBS and $2 \mathrm{mM}$ L-glutamine. The cell suspension was also filtered through a BD-Falcon $70-\mu \mathrm{m}$ cell strainer. Both filtered and non-filtered cells were cultured in DMEM or DMEM/F12 medium containing 2.5\% FBS and $2 \mathrm{mM}$ L-glutamine individually, cultured on both Corning collagen-coated and non-coated plates or T75 flasks, and stored in a humid atmosphere of (Corning, Corning, NY, USA) at $37^{\circ} \mathrm{C}$ plus $5 \% \mathrm{CO}_{2}$. Half of the culture medium was changed every 2-3 days and the culture plate was routinely checked for adherent cells. This xenoline was generated at our institution. Furthermore, the xenoline was authenticated by STR and confirmed to be negative for mycoplasma, as described above. MYC-RAD21 copy numbers were obtained from whole genome sequencing (Table S7).

\subsection{Western Blot Analysis}

Cells were lysed with RIPA buffer containing EDTA-free Complete Protease Inhibitor Cocktail as per the manufacturer's instructions (Roche Diagnostics, Indianapolis, IN, USA), and 1\% phosphatase inhibitor 3 as previously described Sigma $[25,46]$. The protein concentration was determined by the $D C$ Protein Assay (Bio-Rad, Hercules, CA, USA) and quantified using BioTek Synergy H4 (BioTek, Winooski, VT, USA)). For Western blot analysis, proteins were separated on TGX Stain-Free ${ }^{\mathrm{TM}}$ gels (Bio-Rad), along with Precision Plus Protein ${ }^{\mathrm{TM}}$ All-Blue Standards (Bio-Rad), and transferred to an LF PVDF 
membrane using the Trans-Blot Turbo Transfer System (Bio-Rad). Membranes were blocked for $1 \mathrm{~h}$ at room temperature in 5\% non-fat dry milk in TBS-T ( $137 \mathrm{mM} \mathrm{NaCl}, 20 \mathrm{mM}$ Tris, and $0.02 \%$ Tween 20$)$. Membranes were washed following antibody incubation with TBS-T for a total of three 10-min washes. The correct molecular weight for each protein was confirmed by the Precision Plus All Blue Standard (Bio-Rad). The following antibodies were diluted in either $5 \%$ non-fat dry milk or $5 \%$ BSA in TBS-T, as per the manufacturer's instructions, and used for detection: Rabbit anti-phospho-CHK1 serine 345 [pCHK1-Ser345] (56 kDa, cat\# 2348, Cell Signaling Technology, Danvers, MA, USA); mouse IgG1 anti-CHK1 [2G1D5] (56 kDa, cat\# 2360, Cell Signaling Technology); mouse anti-c-Myc [9E10] (57-65 kDa, cat\# MA1-980, ThermoFisher); rabbit anti-BRD2 [D89B4] (110 kDa, cat\# 5848, Cell Signaling Technology); mouse anti-BRD3 [2088C3a] (80 kDa, cat\# sc-81202, Santa Cruz Biotechnology, Dallas, TX, USA); rabbit anti-BRD4 [E2A7X] (200 kDa, cat\# 13440, Cell Signaling Technology); rabbit anti-RAD21 (130 kDa, cat\# 4321, Cell Signaling Technology); rabbit anti-phospho-H2A.X serine 139 [p-H2AX-Ser139] (15 kDa, cat\# 2577, Cell Signaling Technology); rabbit anti-H2A.X (15 kDa, cat\# 2595, Cell Signaling Technology); rabbit anti-cleaved PARP [D64E10] (89 kDa, cat\# 5625, Cell Signaling Technology); rabbit anti-PARP (89 and $116 \mathrm{kDa}$, cat\# 9542, Cell Signaling Technology); and rabbit anti-vinculin [E1E9V] (124 kDa, cat\# 13901, Cell Signaling Technology). Blots were then incubated with the appropriate horseradish peroxidase-conjugated secondary antibody, diluted 1:5000 in 5\% non-fat dry milk for $1 \mathrm{~h}$ at room temperature (Anti-mouse IgG HRP-conjugate, cat\# W4021, Promega; Anti-rabbit IgG HRP-conjugate, cat\# W4011, Promega). Membranes were again washed following secondary antibody incubation with TBS-T for a total of three 10-min washes. Proteins were detected using the SuperSignal Western Chemiluminescent Substrate (Thermo Scientific, Grand Island, NY, USA) and imaged using the Bio-Rad ChemiDoc Imaging System (Bio-Rad). The quantification of protein expression was done using the Image Lab software (Bio-Rad) and proteins of interest were normalized to total protein, as quantitated from the corresponding blot, and expressed relative to control cells (NHOSTs), media- or vehicle-treated control cells, or non-targeting control siRNA. For phosphorylated CHK1 and H2AX, protein levels were also quantitated and normalized to their total protein levels, respectively.

\subsection{Statistical Analysis}

For in vitro drug combination studies, IC50 values and combination indices were determined by CalcuSyn v2 (BioSoft), as previously described [106]. A Bliss independence model was used to evaluate combination effects on an efficacy scale [108]. The Bliss expected value was calculated using the equation $(A+B)-(A \times B)$, in which $A$ and $B$ are the percentage of growth inhibition induced by agents $\mathrm{A}$ and $\mathrm{B}$ for a given pair of doses. Values of the difference between the Bliss expected growth inhibition and the observed growth inhibition of approximately $0 \%$ indicate additivity, $>0 \%$ indicate synergy, and $<0 \%$ indicate antagonism. Results are reported as mean \pm SD. Data were considered significant at $p<0.05$. Saos2 flank tumor xenograft and TT2-77 PDX tumor volume data were analyzed by a two-way repeated measures ANOVA (one factor repetition), followed by a Holm-Sidak post-hoc pairwise multiple comparisons test using GraphPad Prism Software (GraphPad, Inc., San Diego, CA, USA) and SigmaPlot 11.2 (Systat Software, Inc., San Jose, CA, USA). The tumor volume is presented as the mean \pm SEM and was determined $3 \times$ per week. Saos2 CDX and TT2-77 PDX survival was assessed by Kaplan-Meier plots and analyzed by the log-rank test.

\section{Conclusions}

Discoveries made possible by systems biology approaches provide innovative and rational approaches for exploring and prioritizing new possibilities for pediatric cancer treatment. Through an integrative bioinformatic analysis of CNVs, gene expression, patient outcome data, and network analysis, we identified MYC-RAD21+ as a prognostic signature that is predictive of poor overall survival in pediatric and AYA OS. This approach demonstrates the feasibility of using a CNV to identify a dysregulated network that can be therapeutically targeted at multiple points of regulation. Our data indicate that dual-inhibition of BET + CHK1 was safe and efficacious in preclinical pediatric and AYA 
OS models harboring the MYC-RAD21+ signature. The integration and implementation of this type of precision genomics-based methodology will help to prioritize the testing of innovative treatments to target therapeutically actionable prognostic signatures at the time of diagnosis for improving clinical outcomes in pediatric and AYA OS patients.

Supplementary Materials: The following are available online at http://www.mdpi.com/2072-6694/12/9/2426/s1: Table S1a: Clinical annotations and overview of the TARGET database for OS patient sample genes, CNVs, gene expression, and patient outcomes; Table S1b: Clinical annotations and overview of the GEO Series ID GSE16091 database for OS patient sample genes, gene expression, and patient outcomes; Table S2: Gene annotations from the TARGET database show significant correlations $(p<0.05)$ between CNVs, gene expression, and overall survival; Table S3: GEO Serials ID GSE16091 database: Significant correlation between gene expression and overall survival in pediatric OS; Table S4: Summary of correlation analyses of the 71 overlapping genes from TARGET and GSE16091 datasets with overall survival (Cox Regression Analysis; $p<0.05$ ); Table S5: Cox regression analysis conducted on OS pediatric patients from the TARGET database $(n=85)$ : CNVs in 2640 genes significantly correlate with an increased risk for relapse in pediatric OS patients with 260 of these genes present on chromosome 8; Table S6a: Network Analysis (Ingenuity Pathway Analysis-IPA) of genes with CNVs that are significantly associated with overall survival; Table S6b: Protein degree of significant CNVs in the STRING database (https://string-db.org/); Table S6c: Disease annotation of the significant CNVs based on Ingenuity Pathway Analysis (IPA) associated with connective tissue disorders; Table S6d: Pathway enrichment analysis of CNVs in TARGET; Table S7: MYC-RAD21 copies in established OS cell lines, in a TT2-77 primary diagnostic sample, and in TT2-77 PDX samples; Figure S1: Alterations in MYC and RAD21 CNVs correlate with poor survival in pediatric and AYA OS patients; Figure S2: Validation of targets in established OS cell lines; Figure S3: Validation of targets in TT2-77 PDX and PDX-derived OS Xenoline; Figure S4: Quantification of cleaved-PARP protein expression in Saos2 cells treated with a single agent or combination BETi + CHK1i; Figure S5: Combination BETi/OTX-015 + CHK1i/SRA737 inhibits cell growth in OS cells; Figure S6: Quantification of protein expression in Saos2 cells treated with a single agent or combination BETi + CHK1i; Figure S7: Knock down of BRD4 via siRNA does not decrease MYC, CHK1, or other BET proteins; Figure S8: Dual-inhibition of BET and CHK1 effectively decreases tumor growth and is well-tolerated in MYC-RAD21+ Saos2 CDX; Figure S9: Inhibition of BET in combination with the CHK1 inhibitor is effectively decreases tumor growth kinetics and is well-tolerated in an AYA relapsed MYC-RAD21+ PDX; Figure S10: Single-agent or BETi + CHK1i combination therapy does not affect the organ tissue integrity.

Author Contributions: Software, formal analysis, and data curation: query and bioinformatics analyses of publicly-available datasets were conducted by L.C., L.L., and S.T. Validation, investigation and formal analysis: target expression and cell growth assays was conducted by P.H.P., C.N.Y., Q.T., F.B., J.D., B.J.B., E.A.D., H.E.S., A.E., and J.S. Resources and methodology: TT2-77 PDX and PDX-derived cell lines were developed and characterized by M.R.S., K.B.-V., B.J.B., A.L.S., M.A.T., K.L.C., T.E.B., L.D.W., S.D., M.S.M., M.J.F., S.B., J.L.R. and K.E.P. Visualization: pathology and confirmation of the original TT2-77 sample for patient diagnosis was done by E.A.A. Writing original draft, review, editing were completed by P.H.P, L.C., L.L., M.R.S., M.E.M., H.E.S., J.L.R., and K.E.P. Conceptualization, supervision, project administration, and funding acquisition: K.E.P., J.L.R., L.L., All authors have read and agreed to the published version of the manuscript.

Funding: This research was funded by the NIH/Eunice Kennedy Shriver NICHD U54HD16014 (P.H.P., L.C., M.R.S., B.J.B., J.D., K.B.V., M.E.M., M.S.M., K.E.P., and J.L.R.), the NIH/NCI Cancer Center Support Grant P30CA082709 awarded to the Indiana University Simon Comprehensive Cancer Center (A.L.S., M.T., K.C., B.J.B., and K.E.P.), the Jeff Gordon Research Foundation (P.H.P. and J.L.R.), the Caroline Symmes Cancer Endowment (J.L.R.), the Tyler Trent Cancer Research Endowment for the Riley Hospital for Children IU-Health (P.H.P., M.R.S., K.E.P., and J.L.R.), Curing Kids Cancer (P.H.P., A.E., K.E.P., and J.L.R.), Morgan Adams Foundation (P.H.P., J.L.R., K.E.P.), and the Indiana University Grand Challenge-Precision Health Initiative (P.H.P., C.N.H., K.B.V., J.D., M.R.S., M.D.M., T.E.B., L.D.W., K.E.P., and J.L.R.).

Acknowledgments: This study is dedicated to the memory of Tyler Trent, who passed away on January 1, 2019 from OS. The Precision Genomics team at the Riley Hospital for Children will always remember Tyler for his courageous battle with OS, his passion for cancer advocacy, and the generous donation of his OS tumor tissue for research. We acknowledge George E. Sandusky in the IU School of Medicine Department of Pathology for processing and pathology analysis of H\&E-stained slides. We also thank Art Baluyut for his support and insightful discussions. We acknowledge Emily Sims and Matthew Repass for their expert technical assistance with the analysis of apoptosis by flow cytometry. Grainne and Clay Owen founded the Curing Kids Cancer, a 501(c) nonprofit devoted to funding cutting edge pediatric cancer therapies, after they lost their son, Killian, to leukemia in 2003. He was nine years old. Since it was founded in 2005, Curing Kids Cancer has raised more than $\$ 17$ million to fund new childhood cancer treatments and pediatric cancer research. For more information on how to help, please contact Curing Kids Cancer at 1-866-933-CURE (2873) or visit curingkidscancer.org $<$ http://curingkidscancer.org/> to learn more.

Conflicts of Interest: The authors declare no conflict of interest. 


\section{References}

1. Benjamin, R.S.; Patel, S.R. Pediatric and Adult Osteosarcoma: Comparisons and Contrasts in Presentation and Therapy. In Pediatric and Adolescent Osteosarcoma; Jaffe, N., Bruland, O.S., Bielack, S., Eds.; Springer US: Boston, MA, USA, 2010; pp. 355-363. [CrossRef]

2. Reed, D.R.; Hayashi, M.; Wagner, L.; Binitie, O.; Steppan, D.A.; Brohl, A.S.; Shinohara, E.T.; Bridge, J.A.; Loeb, D.M.; Borinstein, S.C.; et al. Treatment pathway of bone sarcoma in children, adolescents, and young adults. Cancer 2017, 123, 2206-2218. [CrossRef] [PubMed]

3. Taran, S.J.; Taran, R.; Malipatil, N.B. Pediatric Osteosarcoma: An Updated Review. Indian J. Med. Paediatr. Oncol. Off. J. Indian Soc. Med. Paediatr. Oncol. 2017, 38, 33-43. [CrossRef] [PubMed]

4. Saraf, A.J.; Fenger, J.M.; Roberts, R.D. Osteosarcoma: Accelerating Progress Makes for a Hopeful Future. Front. Oncol. 2018, 8, 4. [CrossRef] [PubMed]

5. Morrow, J.J.; Khanna, C. Osteosarcoma Genetics and Epigenetics: Emerging Biology and Candidate Therapies. Crit. Rev. Oncog. 2015, 20, 173-197. [CrossRef] [PubMed]

6. Xie, L.; Ji, T.; Guo, W. Anti-angiogenesis target therapy for advanced osteosarcoma (Review). Oncol. Rep. 2017, 38, 625-636. [CrossRef]

7. Greenberg, R.G.; Gamel, B.; Bloom, D.; Bradley, J.; Jafri, H.S.; Hinton, D.; Nambiar, S.; Wheeler, C.; Tiernan, R.; Smith, P.B.; et al. Parents' perceived obstacles to pediatric clinical trial participation: Findings from the clinical trials transformation initiative. Contemp. Clin. Trials Commun. 2018, 9, 33-39. [CrossRef] [PubMed]

8. Lamoureux, F.; Baud'huin, M.; Rodriguez Calleja, L.; Jacques, C.; Berreur, M.; Redini, F.; Lecanda, F.; Bradner, J.E.; Heymann, D.; Ory, B. Selective inhibition of BET bromodomain epigenetic signalling interferes with the bone-associated tumour vicious cycle. Nat. Commun. 2014, 5, 3511. [CrossRef]

9. Squire, J.A.; Pei, J.; Marrano, P.; Beheshti, B.; Bayani, J.; Lim, G.; Moldovan, L.; Zielenska, M. High-resolution mapping of amplifications and deletions in pediatric osteosarcoma by use of CGH analysis of cDNA microarrays. Genes Chromosomes Cancer 2003, 38, 215-225. [CrossRef]

10. Kuijjer, M.L.; Rydbeck, H.; Kresse, S.H.; Buddingh, E.P.; Lid, A.B.; Roelofs, H.; Burger, H.; Myklebost, O.; Hogendoorn, P.C.; Meza-Zepeda, L.A.; et al. Identification of osteosarcoma driver genes by integrative analysis of copy number and gene expression data. Genes Chromosomes Cancer 2012, 51, 696-706. [CrossRef]

11. Cheng, L.; Pandya, P.H.; Liu, E.; Chandra, P.; Wang, L.; Murray, M.E.; Carter, J.; Ferguson, M.; Saadatzadeh, M.R.; Bijangi-Visheshsaraei, K.; et al. Integration of genomic copy number variations and chemotherapy-response biomarkers in pediatric sarcoma. BMC Med. Genom. 2019, 12, 23. [CrossRef]

12. Smida, J.; Baumhoer, D.; Rosemann, M.; Walch, A.; Bielack, S.; Poremba, C.; Remberger, K.; Korsching, E.; Scheurlen, W.; Dierkes, C.; et al. Genomic Alterations and Allelic Imbalances Are Strong Prognostic Predictors in Osteosarcoma. Clin. Cancer Res. 2010, 16, 4256-4267. [CrossRef] [PubMed]

13. Lau, C.C.; Harris, C.P.; Lu, X.Y.; Perlaky, L.; Gogineni, S.; Chintagumpala, M.; Hicks, J.; Johnson, M.E.; Davino, N.A.; Huvos, A.G.; et al. Frequent amplification and rearrangement of chromosomal bands 6p12-p21 and 17p11.2 in osteosarcoma. Genes Chromosomes Cancer 2004, 39, 11-21. [CrossRef] [PubMed]

14. Forus, A.; Weghuis, D.O.; Smeets, D.; Fodstad, Ø.; Myklebost, O.; van Kessel, A.G. Comparative genomic hybridization analysis of human sarcomas: II. Identification of novel amplicons at $6 \mathrm{p}$ and 17p in osteosarcomas. Genes Chromosomes Cancer 1995, 14, 15-21. [CrossRef] [PubMed]

15. Stock, C.; Kager, L.; Fink, F.M.; Gadner, H.; Ambros, P.F. Chromosomal regions involved in the pathogenesis of osteosarcomas. Genes Chromosomes Cancer 2000, 28, 329-336. [CrossRef]

16. Man, T.K.; Lu, X.Y.; Jaeweon, K.; Perlaky, L.; Harris, C.P.; Shah, S.; Ladanyi, M.; Gorlick, R.; Lau, C.C.; Rao, P.H. Genome-wide array comparative genomic hybridization analysis reveals distinct amplifications in osteosarcoma. BMC Cancer 2004, 4, 45. [CrossRef]

17. Martin, J.W.; Yoshimoto, M.; Ludkovski, O.; Thorner, P.S.; Zielenska, M.; Squire, J.A.; Nuin, P.A. Analysis of segmental duplications, mouse genome synteny and recurrent cancer-associated amplicons in human chromosome 6p21-p12. Cytogenet. Genome Res. 2010, 128, 199-213. [CrossRef]

18. Entz-Werle, N.; Lavaux, T.; Metzger, N.; Stoetzel, C.; Lasthaus, C.; Marec, P.; Kalifa, C.; Brugieres, L.; Pacquement, H.; Schmitt, C.; et al. Involvement of MET/TWIST/APC combination or the potential role of ossification factors in pediatric high-grade osteosarcoma oncogenesis. Neoplasia 2007, 9, 678-688. [CrossRef] 
19. Zielenska, M.; Bayani, J.; Pandita, A.; Toledo, S.; Marrano, P.; Andrade, J.; Petrilli, A.; Thorner, P.; Sorensen, P.; Squire, J.A. Comparative genomic hybridization analysis identifies gains of 1p35 p36 and chromosome 19 in osteosarcoma. Cancer Genet. Cytogenet. 2001, 130, 14-21. [CrossRef]

20. Pompetti, F.; Rizzo, P.; Simon, R.M.; Freidlin, B.; Mew, D.J.; Pass, H.I.; Picci, P.; Levine, A.S.; Carbone, M. Oncogene alterations in primary, recurrent, and metastatic human bone tumors. J. Cell. Biochem. 1996, 63, 37-50. [CrossRef]

21. Ladanyi, M.; Park, C.K.; Lewis, R.; Jhanwar, S.C.; Healey, J.H.; Huvos, A.G. Sporadic amplification of the MYC gene in human osteosarcomas. Diagn. Mol. Pathol. Am. J. Surg. Pathol. Part B 1993, 2, 163-167. [CrossRef]

22. Yotov, W.V.; Hamel, H.; Rivard, G.E.; Champagne, M.A.; Russo, P.A.; Leclerc, J.M.; Bernstein, M.L.; Levy, E. Amplifications of DNA primase 1 (PRIM1) in human osteosarcoma. Genes Chromosomes Cancer 1999, 26, 62-69. [CrossRef]

23. Lonardo, F.; Ueda, T.; Huvos, A.G.; Healey, J.; Ladanyi, M. p53 and MDM2 alterations in osteosarcomas: Correlation with clinicopathologic features and proliferative rate. Cancer 1997, 79, 1541-1547. [CrossRef]

24. Tarkkanen, M.; Karhu, R.; Kallioniemi, A.; Elomaa, I.; Kivioja, A.H.; Nevalainen, J.; Bohling, T.; Karaharju, E.; Hyytinen, E.; Knuutila, S.; et al. Gains and losses of DNA sequences in osteosarcomas by comparative genomic hybridization. Cancer Res. 1995, 55, 1334-1338. [PubMed]

25. Henriksen, J.; Aagesen, T.H.; Maelandsmo, G.M.; Lothe, R.A.; Myklebost, O.; Forus, A. Amplification and overexpression of COPS3 in osteosarcomas potentially target TP53 for proteasome-mediated degradation. Oncogene 2003, 22, 5358-5361. [CrossRef]

26. Yan, T.; Wunder, J.S.; Gokgoz, N.; Gill, M.; Eskandarian, S.; Parkes, R.K.; Bull, S.B.; Bell, R.S.; Andrulis, I.L. COPS3 amplification and clinical outcome in osteosarcoma. Cancer 2007, 109, 1870-1876. [CrossRef]

27. Atiye, J.; Wolf, M.; Kaur, S.; Monni, O.; Bohling, T.; Kivioja, A.; Tas, E.; Serra, M.; Tarkkanen, M.; Knuutila, S. Gene amplifications in osteosarcoma-CGH microarray analysis. Genes Chromosomes Cancer 2005, 42, 158-163. [CrossRef]

28. Nielsen, G.P.; Burns, K.L.; Rosenberg, A.E.; Louis, D.N. CDKN2A gene deletions and loss of p16 expression occur in osteosarcomas that lack RB alterations. Am. J. Pathol. 1998, 153, 159-163. [CrossRef]

29. Tsuchiya, T.; Sekine, K.; Hinohara, S.; Namiki, T.; Nobori, T.; Kaneko, Y. Analysis of the p16INK4, p14ARF, p15, TP53, and MDM2 genes and their prognostic implications in osteosarcoma and Ewing sarcoma. Cancer Genet. Cytogenet. 2000, 120, 91-98. [CrossRef]

30. Miller, C.W.; Aslo, A.; Campbell, M.J.; Kawamata, N.; Lampkin, B.C.; Koeffler, H.P. Alterations of the p15, p16,and p18 genes in osteosarcoma. Cancer Genet. Cytogenet. 1996, 86, 136-142. [CrossRef]

31. Patino-Garcia, A.; Pineiro, E.S.; Diez, M.Z.; Iturriagagoitia, L.G.; Klussmann, F.A.; Ariznabarreta, L.S. Genetic and epigenetic alterations of the cell cycle regulators and tumor suppressor genes in pediatric osteosarcomas. J. Pediatric Hematol. Oncol. 2003, 25, 362-367. [CrossRef]

32. Mendoza, S.; David, H.; Gaylord, G.M.; Miller, C.W. Allelic loss at 10q26 in osteosarcoma in the region of the BUB3 and FGFR2 genes. Cancer Genet. Cytogenet. 2005, 158, 142-147. [CrossRef]

33. Yan, G.N.; Lv, Y.F.; Guo, Q.N. Advances in osteosarcoma stem cell research and opportunities for novel therapeutic targets. Cancer Lett. 2016, 370, 268-274. [CrossRef] [PubMed]

34. Martin, J.W.; Squire, J.A.; Zielenska, M. The genetics of osteosarcoma. Sarcoma 2012, 2012, 627254. [CrossRef] [PubMed]

35. Varshney, J.; Scott, M.C.; Largaespada, D.A.; Subramanian, S. Understanding the Osteosarcoma Pathobiology: A Comparative Oncology Approach. Vet. Sci. 2016, 3, 3. [CrossRef]

36. Taylor, B.S.; Barretina, J.; Maki, R.G.; Antonescu, C.R.; Singer, S.; Ladanyi, M. Advances in sarcoma genomics and new therapeutic targets. Nat. Rev. Cancer 2011, 11, 541-557. [CrossRef] [PubMed]

37. Rickel, K.; Fang, F.; Tao, J. Molecular genetics of osteosarcoma. Bone 2017, 102, 69-79. [CrossRef] [PubMed]

38. Flores, R.J.; Li, Y.; Yu, A.; Shen, J.; Rao, P.H.; Lau, S.S.; Vannucci, M.; Lau, C.C.; Man, T.K. A systems biology approach reveals common metastatic pathways in osteosarcoma. BMC Syst. Biol. 2012, 6, 50. [CrossRef] [PubMed]

39. Zhang, Y.; Yang, J.; Zhao, N.; Wang, C.; Kamar, S.; Zhou, Y.; He, Z.; Yang, J.; Sun, B.; Shi, X.; et al. Progress in the chemotherapeutic treatment of osteosarcoma. Oncol. Lett. 2018, 16, 6228-6237. [CrossRef]

40. Remondini, D. Systems Biology approaches to cancer: Towards new therapeutical strategies and personalized approaches. Mol. Cell. Oncol. 2019, 6, 1561118. [CrossRef] 
41. Chuang, H.Y.; Hofree, M.; Ideker, T. A decade of systems biology. Annu. Rev. Cell Dev. Biol. 2010, 26, 721-744. [CrossRef]

42. Hasin, Y.; Seldin, M.; Lusis, A. Multi-omics approaches to disease. Genome Biol. 2017, 18, 83. [CrossRef] [PubMed]

43. Somvanshi, P.R.; Venkatesh, K.V. A conceptual review on systems biology in health and diseases: From biological networks to modern therapeutics. Syst. Synth. Biol. 2014, 8, 99-116. [CrossRef] [PubMed]

44. Ma, X.; Liu, Y.; Liu, Y.; Alexandrov, L.B.; Edmonson, M.N.; Gawad, C.; Zhou, X.; Li, Y.; Rusch, M.C.; Easton, J.; et al. Pan-cancer genome and transcriptome analyses of 1,699 paediatric leukaemias and solid tumours. Nature 2018, 555, 371-376. [CrossRef] [PubMed]

45. Deb, S.; Xu, H.; Tuynman, J.; George, J.; Yan, Y.; Li, J.; Ward, R.L.; Mortensen, N.; Hawkins, N.J.; McKay, M.J.; et al. RAD21 cohesin overexpression is a prognostic and predictive marker exacerbating poor prognosis in KRAS mutant colorectal carcinomas. Br. J. Cancer 2014, 110, 1606-1613. [CrossRef]

46. Yu, L.; Guo, W.; Zhao, S.; Tang, J.; Liu, J. Knockdown of Mad2 induces osteosarcoma cell apoptosis-involved Rad21 cleavage. J. Orthop. Sci. Off. J. Jpn. Orthop. Assoc. 2011, 16, 814-820. [CrossRef]

47. Rohban, S.; Campaner, S. Myc induced replicative stress response: How to cope with it and exploit it. Biochim. Biophys. Acta Gene Regul. Mech. 2015, 1849, 517-524. [CrossRef]

48. Campaner, S.; Amati, B. Two sides of the Myc-induced DNA damage response: From tumor suppression to tumor maintenance. Cell Div. 2012, 7, 6. [CrossRef]

49. Gabay, M.; Li, Y.; Felsher, D.W. MYC Activation Is a Hallmark of Cancer Initiation and Maintenance. Cold Spring Harb. Perspect. Med. 2014, 4, a014241. [CrossRef]

50. Gu, L.; Chu, P.; Lingeman, R.; McDaniel, H.; Kechichian, S.; Hickey, R.J.; Liu, Z.; Yuan, Y.C.; Sandoval, J.A.; Fields, G.B.; et al. The Mechanism by Which MYCN Amplification Confers an Enhanced Sensitivity to a PCNA-Derived Cell Permeable Peptide in Neuroblastoma Cells. EBioMedicine 2015, 2, 1923-1931. [CrossRef]

51. Zhang, J.; Dai, Q.; Park, D.; Deng, X. Targeting DNA Replication Stress for Cancer Therapy. Genes 2016, 7, 51. [CrossRef]

52. Hills, S.A.; Diffley, J.F.X. DNA Replication and Oncogene-Induced Replicative Stress. Curr. Biol. 2014, 24, R435-R444. [CrossRef] [PubMed]

53. Feng, W.; Dean, D.C.; Hornicek, F.J.; Spentzos, D.; Hoffman, R.M.; Shi, H.; Duan, Z. Myc is a prognostic biomarker and potential therapeutic target in osteosarcoma. Ther. Adv. Med. Oncol. 2020, 12, 1758835920922055. [CrossRef] [PubMed]

54. Ubhi, T.; Brown, G.W. Exploiting DNA Replication Stress for Cancer Treatment. Cancer Res. 2019, 79, 1730-1739. [CrossRef] [PubMed]

55. Khoueiry, P.; Ward Gahlawat, A.; Petretich, M.; Michon, A.M.; Simola, D.; Lam, E.; Furlong, E.E.; Benes, V.; Dawson, M.A.; Prinjha, R.K.; et al. BRD4 bimodal binding at promoters and drug-induced displacement at Pol II pause sites associates with I-BET sensitivity. Epigenetics Chromatin 2019, 12, 39. [CrossRef]

56. Li, W.; Gupta, S.K.; Han, W.; Kundson, R.A.; Nelson, S.; Knutson, D.; Greipp, P.T.; Elsawa, S.F.; Sotomayor, E.M.; Gupta, M. Targeting MYC activity in double-hit lymphoma with MYC and BCL2 and/or BCL6 rearrangements with epigenetic bromodomain inhibitors. J. Hematol. Oncol. 2019, 12, 73. [CrossRef]

57. Zeman, M.K.; Cimprich, K.A. Causes and Consequences of Replication Stress. Nat. Cell Biol. 2014, 16, 2-9. [CrossRef]

58. Berenguer-Daizé, C.; Astorgues-Xerri, L.; Odore, E.; Cayol, M.; Cvitkovic, E.; Noel, K.; Bekradda, M.; MacKenzie, S.; Rezai, K.; Lokiec, F.; et al. OTX015 (MK-8628), a novel BET inhibitor, displays in vitro and in vivo antitumor effects alone and in combination with conventional therapies in glioblastoma models. Int. J. Cancer 2016, 139, 2047-2055. [CrossRef]

59. Zhang, J.; Dulak, A.M.; Hattersley, M.M.; Willis, B.S.; Nikkilä, J.; Wang, A.; Lau, A.; Reimer, C.; Zinda, M.; Fawell, S.E.; et al. BRD4 facilitates replication stress-induced DNA damage response. Oncogene 2018, 37, 3763-3777. [CrossRef]

60. Takashima, Y.; Kikuchi, E.; Kikuchi, J.; Suzuki, M.; Kikuchi, H.; Maeda, M.; Shoji, T.; Furuta, M.; Kinoshita, I.; Dosaka-Akita, H.; et al. Bromodomain and extraterminal domain inhibition synergizes with WEE1-inhibitor AZD1775 effect by impairing nonhomologous end joining and enhancing DNA damage in nonsmall cell lung cancer. Int. J. Cancer. 2020, 146, 1114-1124. [CrossRef] 
61. Rohban, S.; Cerutti, A.; Morelli, M.J.; d'Adda di Fagagna, F.; Campaner, S. The cohesin complex prevents Myc-induced replication stress. Cell Death Dis. 2017, 8, e2956. [CrossRef]

62. Sayles, L.C.; Breese, M.R.; Koehne, A.L.; Leung, S.G.; Lee, A.G.; Liu, H.Y.; Spillinger, A.; Shah, A.T.; Tanasa, B.; Straessler, K.; et al. Genome-Informed Targeted Therapy for Osteosarcoma. Cancer Discov. 2019, 9, 46-63. [CrossRef] [PubMed]

63. Plummer, E.R.; Kristeleit, R.S.; Cojocaru, E.; Haris, N.M.; Carter, L.; Jones, R.H.; Blagden, S.P.; Evans, T.R.J.; Arkenau, H.T.; Sarker, D.; et al. A first-in-human phase I/II trial of SRA737 (a Chk1 Inhibitor) in subjects with advanced cancer. J. Clin. Oncol. 2019, 37, 3094. [CrossRef]

64. Wicaksono, B.D. Investigating the Predictors of Sensitivity to the Chk1 Inhibitor PF-00477736 in Melanoma. Master's Thesis, The University of Melbourne, Melbourne, Australia, 2013.

65. Dorsett, D.; Ström, L. The ancient and evolving roles of cohesin in gene expression and DNA repair. Curr. Biol. 2012, 22, R240-R250. [CrossRef] [PubMed]

66. Duan, Y.; Guan, Y.; Qin, W.; Zhai, X.; Yu, B.; Liu, H. Targeting Brd4 for cancer therapy: Inhibitors and degraders. Medchemcomm 2018, 9, 1779-1802. [CrossRef] [PubMed]

67. Tarkkanen, M.; Elomaa, I.; Blomqvist, C.; Kivioja, A.H.; Kellokumpu-Lehtinen, P.; Böhling, T.; Valle, J.; Knuutila, S. DNA sequence copy number increase at 8q: A potential new prognostic marker in high-grade osteosarcoma. Int. J. Cancer 1999, 84, 114-121. [CrossRef]

68. Liu, Y.; Sun, W.; Ma, X.; Hao, Y.; Liu, G.; Hu, X.; Shang, H.; Wu, P.; Zhao, Z.; Liu, W. Logistic regression analysis for the identification of the metastasis-associated signaling pathways of osteosarcoma. Int. J. Mol. Med. 2018, 41, 1233-1244. [CrossRef]

69. Takeba, Y.; Nagafuchi, H.; Takeno, M.; Kashiwakura, J.I.; Suzuki, N. Txk, a Member of Nonreceptor Tyrosine Kinase of Tec Family, Acts as a Th1 Cell-Specific Transcription Factor and Regulates IFN- $\gamma$ Gene Transcription. J. Immunol. 2002, 168, 2365-2370. [CrossRef]

70. Xu, Z.; Wang, T. miR-214 promotes the proliferation and invasion of osteosarcoma cells through direct suppression of LZTS1. Biochem. Biophys. Res. Commun. 2014, 449, 190-195. [CrossRef]

71. Yao, P.; Wang, Z.B.; Ding, Y.Y.; Ma, J.M.; Hong, T.; Pan, S.N.; Zhang, J. Regulatory network of differentially expressed genes in metastatic osteosarcoma. Mol. Med. Rep. 2015, 11, 2104-2110. [CrossRef]

72. Cabeza-Arvelaiz, Y.; Sepulveda, J.L.; Lebovitz, R.M.; Thompson, T.C.; Chinault, A.C. Functional identification of LZTS1 as a candidate prostate tumor suppressor gene on human chromosome 8p22. Oncogene 2001, 20, 4169-4179. [CrossRef]

73. Myhre, S.; Lingjærde, O.C.; Hennessy, B.T.; Aure, M.R.; Carey, M.S.; Alsner, J.; Tramm, T.; Overgaard, J.; Mills, G.B.; Børresen-Dale, A.L.; et al. Influence of DNA copy number and mRNA levels on the expression of breast cancer related proteins. Mol. Oncol. 2013, 7, 704-718. [CrossRef]

74. Hong, D.; Infante, J.; Janku, F.; Jones, S.; Nguyen, L.M.; Burris, H.; Naing, A.; Bauer, T.M.; Piha-Paul, S.; Johnson, F.M.; et al. Phase I Study of LY2606368, a Checkpoint Kinase 1 Inhibitor, in Patients With Advanced Cancer. J. Clin. Oncol. 2016, 34, 1764-1771. [CrossRef]

75. Chaitanya, G.V.; Steven, A.J.; Babu, P.P. PARP-1 cleavage fragments: Signatures of cell-death proteases in neurodegeneration. Cell Commun. Signal. 2010, 8, 31. [CrossRef]

76. Gaudio, E.; Tarantelli, C.; Ponzoni, M.; Odore, E.; Rezai, K.; Bernasconi, E.; Cascione, L.; Rinaldi, A.; Stathis, A.; Riveiro, E.; et al. Bromodomain inhibitor OTX015 (MK-8628) combined with targeted agents shows strong in vivo antitumor activity in lymphoma. Oncotarget 2016, 7, 58142-58147. [CrossRef] [PubMed]

77. Lewin, J.; Soria, J.C.; Stathis, A.; Delord, J.P.; Peters, S.; Awada, A.; Aftimos, P.G.; Bekradda, M.; Rezai, K.; Zeng, Z.; et al. Phase Ib Trial With Birabresib, a Small-Molecule Inhibitor of Bromodomain and Extraterminal Proteins, in Patients With Selected Advanced Solid Tumors. J. Clin. Oncol. 2018, 36, 3007-3014. [CrossRef] [PubMed]

78. Najafova, Z.; Tirado-Magallanes, R.; Subramaniam, M.; Hossan, T.; Schmidt, G.; Nagarajan, S.; Baumgart, S.J.; Mishra, V.K.; Bedi, U.; Hesse, E.; et al. BRD4 localization to lineage-specific enhancers is associated with a distinct transcription factor repertoire. Nucleic Acids Res. 2016, 45, 127-141. [CrossRef] [PubMed]

79. Engelke, C.G.; Parsels, L.A.; Qian, Y.; Zhang, Q.; Karnak, D.; Robertson, J.R.; Tanska, D.M.; Wei, D.; Davis, M.A.; Parsels, J.D.; et al. Sensitization of pancreatic cancer to chemoradiation by the Chk1 inhibitor MK8776. Clin. Cancer Res. Off. J. Am. Assoc. Cancer Res. 2013, 19, 4412-4421. [CrossRef] [PubMed]

80. Mah, L.J.; El-Osta, A.; Karagiannis, T.C. $\gamma \mathrm{H} 2 \mathrm{AX}$ : A sensitive molecular marker of DNA damage and repair. Leukemia 2010, 24, 679-686. [CrossRef] 
81. Boklan, J. Little patients, losing patience: Pediatric cancer drug development. Mol. Cancer Ther. 2006, 5, 1905-1908. [CrossRef] [PubMed]

82. Cheng, L.; Chandra, P.; Wang, L.; Pollok, K.; Pandya, P.; Murray, M.; Carter, J.; Ferguson, M.; Reza, M.; Mark, M.; et al. Abstract 1281: Genomic structure variation in large screening for pediatric sarcoma therapy. Cancer Res. 2018, 78, 1281. [CrossRef]

83. Moriarity, B.S.; Otto, G.M.; Rahrmann, E.P.; Rathe, S.K.; Wolf, N.K.; Weg, M.T.; Manlove, L.A.; LaRue, R.S.; Temiz, N.A.; Molyneux, S.D.; et al. A Sleeping Beauty forward genetic screen identifies new genes and pathways driving osteosarcoma development and metastasis. Nat. Genet. 2015, 47, 615-624. [CrossRef] [PubMed]

84. Vargas-Rondón, N.; Villegas, V.E.; Rondón-Lagos, M. The Role of Chromosomal Instability in Cancer and Therapeutic Responses. Cancers 2017, 10, 4. [CrossRef] [PubMed]

85. McGuire, J.; Utset-Ward, T.J.; Reed, D.R.; Lynch, C.C. Re-calculating! Navigating through the osteosarcoma treatment roadblock. Pharmacol. Res. 2017, 117, 54-64. [CrossRef] [PubMed]

86. Iranmanesh, S.M.; Guo, N.L. Integrated DNA Copy Number and Gene Expression Regulatory Network Analysis of Non-small Cell Lung Cancer Metastasis. Cancer Inform. 2014, 13, 13-23. [CrossRef]

87. Ren, L.; Chen, L.; Wu, W.; Garribba, L.; Tian, H.; Liu, Z.; Vogel, I.; Li, C.; Hickson, I.D.; Liu, Y. Potential biomarkers of DNA replication stress in cancer. Oncotarget 2017, 8, 36996-37008. [CrossRef]

88. Young, L.A.; O'Connor, L.O.; de Renty, C.; Veldman-Jones, M.H.; Dorval, T.; Wilson, Z.; Jones, D.R.; Lawson, D.; Odedra, R.; Maya-Mendoza, A.; et al. Differential Activity of ATR and WEE1 Inhibitors in a Highly Sensitive Subpopulation of DLBCL Linked to Replication Stress. Cancer Res. 2019, 79, 3762-3775. [CrossRef]

89. Gaillard, H.; García-Muse, T.; Aguilera, A. Replication stress and cancer. Nat. Rev. Cancer 2015, 15, $276-289$. [CrossRef]

90. Burrell, R.A.; McClelland, S.E.; Endesfelder, D.; Groth, P.; Weller, M.C.; Shaikh, N.; Domingo, E.; Kanu, N.; Dewhurst, S.M.; Gronroos, E.; et al. Replication stress links structural and numerical cancer chromosomal instability. Nature 2013, 494, 492-496. [CrossRef]

91. Viktorsson, K.; Lewensohn, R.; Zhivotovsky, B. Systems biology approaches to develop innovative strategies for lung cancer therapy. Cell Death Dis. 2014, 5, e1260. [CrossRef]

92. Xu, H.; Balakrishnan, K.; Malaterre, J.; Beasley, M.; Yan, Y.; Essers, J.; Appeldoorn, E.; Tomaszewski, J.M.; Vazquez, M.; Verschoor, S.; et al. Rad21-cohesin haploinsufficiency impedes DNA repair and enhances gastrointestinal radiosensitivity in mice. PLoS ONE 2010, 5, e12112. [CrossRef]

93. He, H.; Ni, J.; Huang, J.U.N. Molecular mechanisms of chemoresistance in osteosarcoma (Review). Oncol. Lett. 2014, 7, 1352-1362. [CrossRef]

94. Gajduskova, P.; Snijders, A.M.; Kwek, S.; Roydasgupta, R.; Fridlyand, J.; Tokuyasu, T.; Pinkel, D.; Albertson, D.G. Genome position and gene amplification. Genome Biol. 2007, 8, R120. [CrossRef] [PubMed]

95. Shi, Y.; He, R.; Zhuang, Z.; Ren, J.; Wang, Z.; Liu, Y.; Wu, J.; Jiang, S.; Wang, K. A risk signature-based on metastasis-associated genes to predict survival of patients with osteosarcoma. J. Cell. Biochem. 2020, 121, 3479-3490. [CrossRef] [PubMed]

96. Pongas, G.; Kim, M.K.; Min, D.J.; House, C.D.; Jordan, E.; Caplen, N.; Chakka, S.; Ohiri, J.; Kruhlak, M.J.; Annunziata, C.M. BRD4 facilitates DNA damage response and represses CBX5/Heterochromatin protein 1 (HP1). Oncotarget 2017, 8, 51402-51415. [CrossRef] [PubMed]

97. Da-Rè, C.; Halazonetis, T.D. DNA replication stress as an Achilles' heel of cancer. Oncotarget 2015, 6, 1-2. [CrossRef] [PubMed]

98. Fritsche-Guenther, R.; Noske, A.; Ungethum, U.; Kuban, R.J.; Schlag, P.M.; Tunn, P.U.; Karle, J.; Krenn, V.; Dietel, M.; Sers, C. De novo expression of EphA2 in osteosarcoma modulates activation of the mitogenic signalling pathway. Histopathology 2010, 57, 836-850. [CrossRef]

99. Bruford, E.A.; Lush, M.J.; Wright, M.W.; Sneddon, T.P.; Povey, S.; Birney, E. The HGNC Database in 2008: A resource for the human genome. Nucleic Acids Res. 2008, 36, D445-D448. [CrossRef]

100. Irizarry, R.A.; Hobbs, B.; Collin, F.; Beazer-Barclay, Y.D.; Antonellis, K.J.; Scherf, U.; Speed, T.P. Exploration, normalization, and summaries of high density oligonucleotide array probe level data. Biostatistics 2003, 4, 249-264. [CrossRef]

101. Gatto, L.; Christoforou, A. Using R and Bioconductor for proteomics data analysis. Biochim. Biophys. Acta 2014, 1844, 42-51. [CrossRef] 
102. Cox, D.R. Regression Models and Life-Tables. J. R. Stat. Soc. Ser. B Methodol. 1972, 34, 187-220. [CrossRef]

103. Bradburn, M.J.; Clark, T.G.; Love, S.B.; Altman, D.G. Survival analysis part II: Multivariate data analysis—an introduction to concepts and methods. Br. J. Cancer 2003, 89, 431-436. [CrossRef] [PubMed]

104. Robinson, M.D.; McCarthy, D.J.; Smyth, G.K. edgeR: A Bioconductor package for differential expression analysis of digital gene expression data. Bioinformatics 2010, 26, 139-140. [CrossRef] [PubMed]

105. Subramanian, A.; Tamayo, P.; Mootha, V.K.; Mukherjee, S.; Ebert, B.L.; Gillette, M.A.; Paulovich, A.; Pomeroy, S.L.; Golub, T.R.; Lander, E.S.; et al. Gene set enrichment analysis: A knowledge-based approach for interpreting genome-wide expression profiles. Proc. Natl. Acad. Sci. USA 2005, 102, 15545-15550. [CrossRef] [PubMed]

106. Tonsing-Carter, E.; Bailey, B.J.; Saadatzadeh, M.R.; Ding, J.; Wang, H.; Sinn, A.L.; Peterman, K.M.; Spragins, T.K.; Silver, J.M.; Sprouse, A.A.; et al. Potentiation of carboplatin-mediated DNA damage by the Mdm2 modulator Nutlin-3a in a humanized orthotopic breast-to-lung metastatic model. Mol. Cancer Ther. 2015, 14, 2850-2863. [CrossRef]

107. Mattar, M.; McCarthy, C.R.; Kulick, A.R.; Qeriqi, B.; Guzman, S.; de Stanchina, E. Establishing and Maintaining an Extensive Library of Patient-Derived Xenograft Models. Front. Oncol. 2018, 8, 19. [CrossRef]

108. Liu, Q.; Yin, X.; Languino, L.R.; Altieri, D.C. Evaluation of drug combination effect using a Bliss independence dose-response surface model. Stat. Biopharm. Res. 2018, 10, 112-122. [CrossRef]

(C) 2020 by the authors. Licensee MDPI, Basel, Switzerland. This article is an open access article distributed under the terms and conditions of the Creative Commons Attribution (CC BY) license (http://creativecommons.org/licenses/by/4.0/). 